Research Article

\title{
Production and Modification of Cellulose Nanocrystals from Agave tequilana Weber Waste and Its Effect on the Melt Rheology of PLA
}

\author{
Soledad-Cecilia Pech-Cohuo, ${ }^{1}$ Gonzalo Canche-Escamilla $\left(D,{ }^{1}\right.$ Alex Valadez-González, ${ }^{1}$ \\ Victor Vladimir Amilcar Fernández-Escamilla, ${ }^{2}$ and Jorge Uribe-Calderon $\left({ }^{1}{ }^{1}\right.$ \\ ${ }^{1}$ Centro de Investigacion Cientifica de Yucatan, Calle 43 No. 130 entre 32 y 34. Col. Chuburna de Hidalgo, CP 97205 Mérida, \\ YUC, Mexico \\ ${ }^{2}$ Departamento de Ciencias Tecnológicas, Centro Universitario de la Ciénega, Universidad de Guadalajara, Av. Universidad \\ No. 1115, 47819 Ocotlán, JAL, Mexico
}

Correspondence should be addressed to Jorge Uribe-Calderon; jorge.uribe@cicy.mx

Received 20 March 2018; Revised 4 June 2018; Accepted 3 July 2018; Published 9 August 2018

Academic Editor: Hossein Roghani-Mamaqani

Copyright (c) 2018 Soledad-Cecilia Pech-Cohuo et al. This is an open access article distributed under the Creative Commons Attribution License, which permits unrestricted use, distribution, and reproduction in any medium, provided the original work is properly cited.

\begin{abstract}
The production and surface modification of cellulose nanocrystals (CNC) from Agave tequilana Weber waste (ATW) and their effect on the melt rheology of PLA were investigated. For that, CNC were obtained from ATW residues by acid hydrolysis and grafted with 2-ethyl hexyl acrylate (2-EHA) to promote compatibility with nonpolar polymers, such as PLA. The morphology of $\mathrm{CNC}$ occurred as rods, spheres, and the so-called porous network observed by scanning electron microscopy (SEM) and electron transmission microscopy (TEM), and the crystallinity of the cellulose fibers was $\sim 73 \%$ and increased up to $~ 94 \%$ for CNC followed by X-ray diffraction (XRD). The acid hydrolysis and alkali extraction process produce changes on the native cellulose type I from ATW bagasse resulting in a mixture of cellulose type I and II and was preserved after CNC isolation and surface grafting. Polymer grafting was assessed using Fourier-transform infrared spectroscopy (FTIR) and X-ray electron spectroscopy (XPS). Upon surface modification, the grafted CNC presented better thermal stability than CNC pristine evaluated by thermogravimetric analysis (TGA), and the surface energy of the CNC was decreased which could promote CNC dispersion within polymers. Both pristine and surface modified CNC were melt mixed with PLA to produce nanocomposites at different concentrations of CNC. Dynamic time sweep tests showed that the introduction of CNC and CNC/2-EHA decreased the complex viscosity of PLA due to polymer degradation during compounding.
\end{abstract}

\section{Introduction}

Traditionally, CNC have been mainly obtained by acid treatments on cellulose obtaining crystalline nanoparticles virtually free of defects [1]. The conventional sources of cellulose for the production of CNC are wood and cotton fibers; however, crop wastes are alternative sources for obtaining CNC [2-5]. Thus, CNC has been produced from crop waste such as rice [6], banana [2], and coconut [5].

On the other, the blue agave (Agave tequilana Weber) is extensively cultivated for the production of the alcoholic drink denominated tequila. The agave bagasse is the result of agave heads cooked, crushed, and sugar extracted having an estimated cellulose content about 49 wt.\% [7] with an estimated production of $\sim 400,000$ ton/year [8] which represents serious environmental problems [9]. There are very few studies concerning the CNC production from Agave tequilana Weber bagasse with promising results [10].

$\mathrm{CNC}$ can be used as a reinforcer for polymer matrices because of their excellent mechanical properties and unique morphology [11]. However, surface modification of CNC is required to improve its dispersion within hydrophobic matrices and to promote adhesion at the CNC-polymer interface $[12,13]$. In this sense, CNC has been grafted with 
acetic anhydride [14], fatty acids [15, 16], poly(glycidyl methacrylate) [17], and other acrylic monomers to produce nanocomposites based on hydrophobic polymers such as low-density polyethylene (LDPE) and PLA [18]. Polymer nanocomposites containing modified CNC exhibited usually improved properties in comparison with those containing pristine CNC.

On the other hand, rheological characterization of polymer nanocomposites is a powerful technique to evaluate the dispersion of nanoparticles and to investigate the influence of the processing conditions of nanocomposites on the dispersion of the nanoparticles in the polymer matrices; since rheological properties depend strongly on the structure, surface characteristics, size, and shape of the nanoparticles [19].

Some studies have been conducted regarding the rheological behavior of PLA/pristine CNC nanocomposites reporting a significant increase in the complex viscosity, storage, and loss modulus for nanocomposites compared with pure PLA $[20,21]$. Furthermore, it has been reported that the use of grafted CNC (i.e., hydrophobic grafts) improved the rheological properties of the nanocomposites due to the better dispersion of CNC within the polymer matrix [22].

In this study, $\mathrm{CNC}$ were obtained from ATW bagasse by acid hydrolysis and surface modified with poly(2-ethyl hexyl acrylate) to produce a biodegradable reinforcer for polymer matrices [23]. Poly(2-ethyl hexyl acrylate), a biocompatible polymer, was chosen due to its ability to hydrolysis degradation [23]; in addition, the monomers are able to react with the $-\mathrm{OH}$ groups from nanocellulose through free radical graft copolymerization [18]. The main physicochemical characteristics of pristine $\mathrm{CNC}$ and grafted $\mathrm{CNC} / 2$-EHA were determined. The dispersion of pristine and modified CNC within melt compounded PLA nanocomposites was assessed by SEM and TEM. In addition, the influence of CNC loading and surface modification of $\mathrm{CNC}$ on the complex viscosity as a function of time of PLA nanocomposites was evaluated.

\section{Experimental}

2.1. Materials. Raw fibers of ATW bagasse (Sol y Agave de Arandas, SA de CV, Jalisco, Mexico) were used to obtain cellulose using sulfuric acid (Fermont), sodium hydroxide (Fermont), and commercial sodium hypochlorite solution ( $\mathrm{NaClO})$. Inhibitor-free 2-EHA (Aldrich) and cerium and ammonium nitrate (CAN) (Aldrich) were used in the grafting reaction. PLA (NatureWorks 2002D) was used to prepare nanocomposite $\left(\rho=1.25 \mathrm{~g} / \mathrm{cm}^{3}, \quad M F I=\sim 4-8 \mathrm{~g} / 10 \mathrm{~min}\right.$ at $190^{\circ} \mathrm{C}$, according to the technical data sheet).

\subsection{Procedures}

2.2.1. Production of CNC Form ATW Bagasse. First, cellulose fibers were isolated from ATW bagasse fibers by acid hydrolysis and alkaline extraction [2, 24]: briefly, $1 \mathrm{~g}$ of ATW bagasse was mechanically dispersed in $19 \mathrm{~mL}$ of boiling $\mathrm{H}_{2} \mathrm{SO}_{4}$ solution (1\% vol.) for $1 \mathrm{~h}$ and subsequently washed with distilled water; then $1 \mathrm{~g}$ of the above fibers was mechanically mixed with $10 \mathrm{~mL}$ of $\mathrm{NaClO}$ solution at room temperature (3.5 vol.\%) until reaching a $\mathrm{pH}$ of $\sim 9.2$ and washed with distilled water until reaching a $\mathrm{pH}$ of $\sim 7$. Next, $1 \mathrm{~g}$ of the above fibers was mechanically mixed with $10 \mathrm{~g}$ of $\mathrm{NaOH}$ solution (20 wt.\%) for $1 \mathrm{~h}$ and washed with distilled water; and finally, $1 \mathrm{~g}$ of the above fibers was bleached with $12 \mathrm{~mL}$ of $\mathrm{NaClO}$ solution at room temperature (0.5 vol.\%) for $1 \mathrm{~h}$ and washed until reaching a $\mathrm{pH}$ of $\sim 7$. The resulting material was dried at room temperature for $24 \mathrm{~h}$.

$\mathrm{CNC}$ were produced following the procedures reported by Bondeson et al. [1] and Hamad and $\mathrm{Hu}$ [25]: $10.2 \mathrm{~g}$ of cellulose was dispersed mechanically in $100 \mathrm{~mL}$ of deionized water (DI) in an ice bath, and then concentrated $\mathrm{H}_{2} \mathrm{SO}_{4}$ was slowly added until reaching a concentration of $63.5 \mathrm{wt} . \%$. Subsequently, stirring was increased and the mixture was heated $\left(44^{\circ} \mathrm{C}\right)$ for $130 \mathrm{~min}$. The reaction was stopped by pouring $2000 \mathrm{~mL}$ of cold DI water. The suspension was allowed to precipitate for $24 \mathrm{~h}$ producing two phases. The clear phase was discharged and the turbid phase was washed with $2000 \mathrm{~mL}$ deionized water and centrifuged $(15 \mathrm{~min}$ at $3500 \mathrm{rpm})$; this process was repeated three times. Supernatants from the second and third centrifugation cycles were collected and dialyzed against DI water using dialysis membranes (molecular weight $14,000 \mathrm{Da}$ ) until a neutral $\mathrm{pH}$ (1-4 days) was reached. Samples were sonicated using an ultrasonic probe (Sonics, Vibra-Cell, $5 \mathrm{~min}$ in an ice bath); the suspension was stored at $4^{\circ} \mathrm{C}$ and lyophilized to determine the concentration of the suspension.

2.2.2. 2-EHA Grafting on CNC. The 2-EHA grafting was performed using the procedure proposed by Canché-Escamilla et al. [26]: $250 \mathrm{~mL}$ of the CNC suspension $(\sim 0.3 \% w / v)$ was nitrogen bubbled for $1 \mathrm{~h}$ at $30^{\circ} \mathrm{C}$. Subsequently, $0.75 \mathrm{~g}$ of 2 EHA (2-EHA:CNC, $1: 1$ ) and $0.8 \mathrm{~g}$ of CAN (dissolved in $4.6 \mathrm{~mL}$ of $1 \mathrm{~N} \mathrm{HNO}_{3}$ ) was added and stirred for $3 \mathrm{~h}$ at $30^{\circ} \mathrm{C}$. The grafted CNC are washed/centrifuged with DI water three times. The suspension was frozen and lyophilized. Subsequently, the product was mixed with acetone and stirred for $24 \mathrm{~h}$ to dissolve the ungrafted homopolymer. The suspension was filtered and dried in a vacuum oven for $24 \mathrm{~h}$ at $50^{\circ} \mathrm{C}$.

2.2.3. PLA/CNC Nanocomposites. PLA/CNC nanocomposites were obtained in two steps. First, a PLA/CNC (pristine or grafted) master batch (CNC $10 \mathrm{wt} . \%)$ was produced in a Brabender mixing chamber (model PLE-330) at $163^{\circ} \mathrm{C}$ and $30 \mathrm{rpm}$ for $7 \mathrm{~min}$. The masterbatch was then diluted with virgin PLA $(0.5,1$, and $2 \mathrm{CNC}$ wt.\%) using a Brabender conical twin-screw extruder (model PLE-330). Processing temperatures were 150,150 , and $145^{\circ} \mathrm{C}$ in the extruder zones, the screws speed was $5 \mathrm{rpm}$, and a circular die $(5 \mathrm{~mm}$ in diameter) was used at $140^{\circ} \mathrm{C}$. Samples were compression molded (Carver laboratory press, at $180^{\circ} \mathrm{C}$ for $5 \mathrm{~min}$, $2043 \mathrm{kPa}$ clamping force for $5 \mathrm{~min}$, water cooled) to produce $120 \times 120 \times 1 \mathrm{~mm}$ plates for further characterization.

2.2.4. Characterization. The CNC morphology was determined by SEM on dried and lyophilized samples using metal supports and copper tape. The samples were coated with a thin gold layer and observed in a SEM (JEOL JSM-6360, Japan, $10 \mathrm{kV}$ ). The CNC were also observed on a JEOL 1010 transmission electron microscope (TEM), at an 
TABLE 1: Contact angles $\left({ }^{\circ}\right)$, dispersive $\left(\gamma_{s}^{d}\right)$, polar $\left(\gamma_{S}^{P}\right)$ components, and surface energy $\left(\gamma_{s}\right)$ of CNC and CNC/2-EHA.

\begin{tabular}{lcccccc}
\hline Sample & Diiodomethane & $\begin{array}{c}\text { Contact angle } \theta\left(^{\circ}\right) \\
\text { Ethylene glycol }\end{array}$ & Water & $\gamma_{s}^{d}\left(\mathrm{~mJ} / \mathrm{m}^{-2}\right)$ & $\gamma_{s}^{p}\left(\mathrm{~mJ} / \mathrm{m}^{-2}\right)$ & $\gamma_{s}\left(\mathrm{~mJ} / \mathrm{m}^{-2}\right)$ \\
\hline CNC & $26.5 \pm 1.6$ & $27.2 \pm 4.5$ & $44.8 \pm 5.4$ & 30.7 & 22.9 & 53.6 \\
CNC/2-EHA & $25.2 \pm 2.7$ & $52.7 \pm 9.0$ & $73.2 \pm 1.4$ & 36.8 & 5.5 & 42.3 \\
\hline
\end{tabular}

$\gamma_{s}^{d}, \gamma_{s}^{p}$, and $\gamma_{s}$ correspond to the dispersive and polar components and the total surface tension, which are 49.5, 1.3, and 50.8 $\mathrm{mJ} / \mathrm{m}^{-2}$ for diiodomethane; 29,19 , and $48 \mathrm{~mJ} / \mathrm{m}^{-2}$ for ethylene glycol; and $21.8,51$, and $72.8 \mathrm{~mJ} / \mathrm{m}^{-2}$ for water, respectively [14].

accelerating voltage of $100 \mathrm{kV}$, to examine the shape and size of dried CNC. A drop of the diluted solution $(0.001 \% w / v)$ was deposited onto a carbon-coated copper grid and dried afterwards at room temperature for $12 \mathrm{~h}$ before the observation in the microscope. The morphology of PLA/CNC nanocomposites was observed thru the cryogenic fracture surface by SEM. The CNC embedded into the PLA matrix were also examined by TEM. Thin composite samples sliced with a microtome were deposited onto copper grids for observation in the microscope. The particle dimensions were determined using the Image-Pro Plus 6 software.

XRD patterns of the samples were determined using a Diffractometer Bruker D8 Advance $(\mathrm{CuK} \alpha, \lambda=1.5418 \AA$, $40 \mathrm{keV}$ and $30 \mathrm{~mA}$ ), and the crystallinity index was calculated using the Segal equation [27]:

$$
\begin{aligned}
& X_{c} \%=\frac{I_{200}-I_{a m}}{I_{200}} \times 100, \\
& X_{c} \%=\frac{I_{1 \overline{1} 0}-I_{a m}}{I_{1 \overline{1} 0}} \times 100,
\end{aligned}
$$

where $I_{200}$ is the maximum intensity of the (200) lattice diffraction $\left(2 \theta=22.6^{\circ}\right.$ in the case of cellulose I), $I_{1 \overline{1} 0}$ is the maximum intensity of the (1110) diffraction for cellulose II at $2 \theta=20.1^{\circ}$, and $I_{\mathrm{am}}$ is the intensity of the diffraction peak at $2 \theta=18^{\circ}$ (cellulose I) and $2 \theta=16^{\circ}$ (cellulose II) $[28,29]$.

FTIR analysis was performed using a Thermo Scientific Model Nicolet 8700 spectrometer in the transmission mode, with a resolution of $4 \mathrm{~cm}^{-1}$ and 100 scans on $2 \mathrm{mg}$ sample/ $135 \mathrm{mg} \mathrm{KBr}$ tablets. The XPS analysis was performed using Thermo Scientific K-Alpha Surface Analysis equipment, using a monochromatic $\mathrm{K} \alpha$ line, at $40 \mathrm{~W}$ and $12 \mathrm{kV}$.

The thermal stability of the $\mathrm{CNC}$ was determined on a Perkin-Elmer TGA 7 equipment. Samples were heated from $30^{\circ} \mathrm{C}$ to $700^{\circ} \mathrm{C}$ with a heating rate of $10^{\circ} \mathrm{C} / \mathrm{min}$ under a nitrogen flow $(100 \mathrm{~mL} / \mathrm{min})$.

The Owens-Wendt approximation was used to calculate the dispersive and polar contributions of the surface energy of the samples using the contact angles of sessile drops of diiodomethane, ethylene glycol, and water on tablets of pristine and grafted CNC. The liquid surface tension values were taken from literature [14] and are listed in the footnote for Table $1.100 \mathrm{mg}$ CNC tablets were obtained using a $\mathrm{KBr}$ die applying a compression force of $30 \mathrm{kN}$ for $15 \mathrm{~min}$ at room temperature. Contact angle measurements were performed at room temperature using a goniometer (Ramé-Hart Instrument Co.).
Dynamic time-sweep tests were carried out using an AR-2000 rotational stress-controlled rheometer (TA Instruments, New Castle, DE, USA) employing the parallel plate geometry of $25 \mathrm{~mm}$. The linear viscoelastic region (LVR) was initially confirmed by strain amplitude sweeps at constant frequency. Time-sweep experiments at strain amplitude of 0.05 and frequency of $0.5 \mathrm{rads}^{-1}$ were conducted at $165^{\circ} \mathrm{C}$ for $3600 \mathrm{~s}$ using a gap between plates of $0.7 \mathrm{~mm}$ inside LVR. Specimens ( $25 \mathrm{~mm}$ disks) were obtained from compression molded plate.

\section{Results and Discussion}

The cellulose yield from ATW bagasse was 38\% and for the CNC was $28 \%$ from obtained cellulose $(10 \%$ from ATW bagasse); the above are similar to the study reported by Bondeson et al. [1] and Hamad and $\mathrm{Hu}$ [25], who used similar processing conditions to those used in this study but from Picea Norway microcrystalline cellulose and commercial softwood, both were CNC cellulose type I. The conversion of 2-EHA was $7.2 \%$, the addition percentage was $5.4 \%$, and the grafting efficiency was $81.5 \%$. The reduced reactivity of 2-EHA [30] could contribute to the low 2-EHA conversion. The relative high grafting efficiency is due to the $\mathrm{Ce}$ (IV) ions which generate mainly free radicals on the backbone of cellulose [31, 32].

Figure 1(a) shows SEM photographs of a raw ATW fiber which is composed by several cellulose microfibers; after the acid hydrolysis and alkaline extraction, the cellulose fibers were obtained (Figure 1(b)). Figure 1(c) shows clusters of pristine CNC dried directly from a CNC solution; a close-up reveals that the CNC are stacked parallel among them (Figure 1(d)). Similarly, a sample of the $\mathrm{CNC} / 2$ EHA was observed after surface modification process, $\mathrm{CNC/2}$-EHA were identified as aggregates covered by the grafted polymer (red dotted circles on Figures 1(e) and $1(f)$ ). In addition, SEM was performed on lyophilized samples to determine possible changes in the morphology of $\mathrm{CNC}$ due to drying process; surprisingly, pristine CNC are seen as a lamellar structure (Figure $1(\mathrm{~g})$ ), which consists of a large number of thin CNC layers $(\sim 1.7 \mu \mathrm{m}$ thick). No CNC agglomerates or microsize fibers were observed within the thin sheets suggesting that $\mathrm{CNC}$ were self-assembled into thin sheets during the lyophilization process; similar observations were reported by $\mathrm{Li}$ et al. [33] for cellulose I CNC. The self-assembly of CNC is produced due to the confinement of $\mathrm{CNC}$ at the boundaries of ice crystal during freezing process favoring the formation of a chiral nematic structures; the factors affecting 


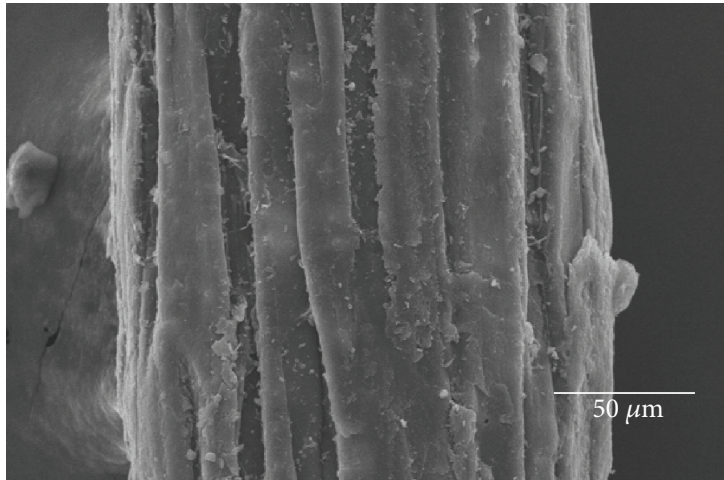

(a)

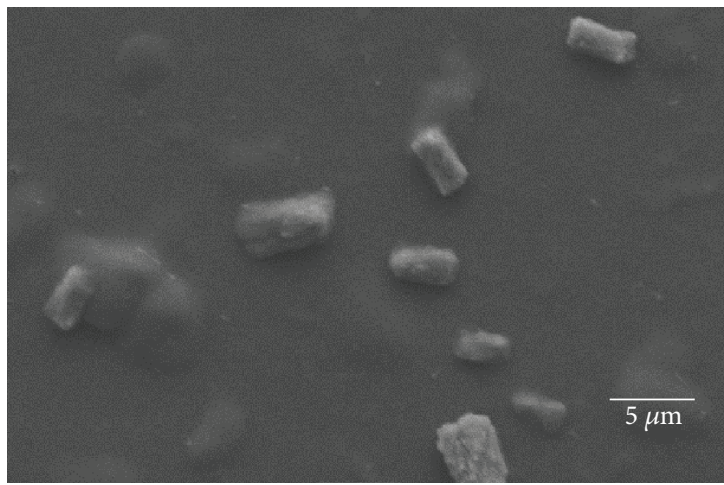

(c)

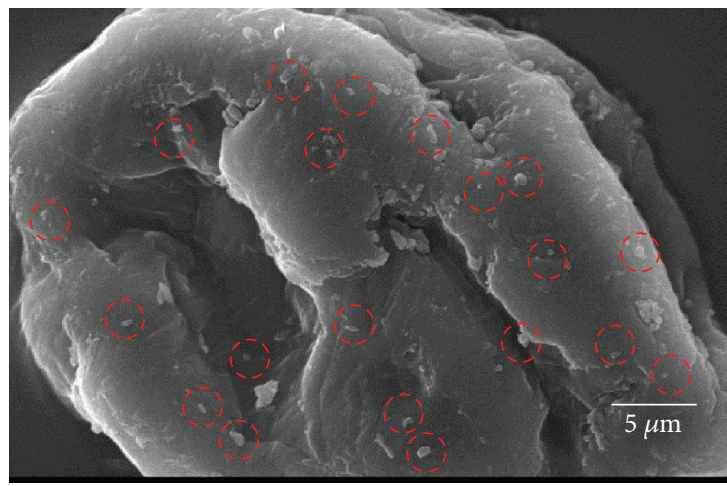

(e)

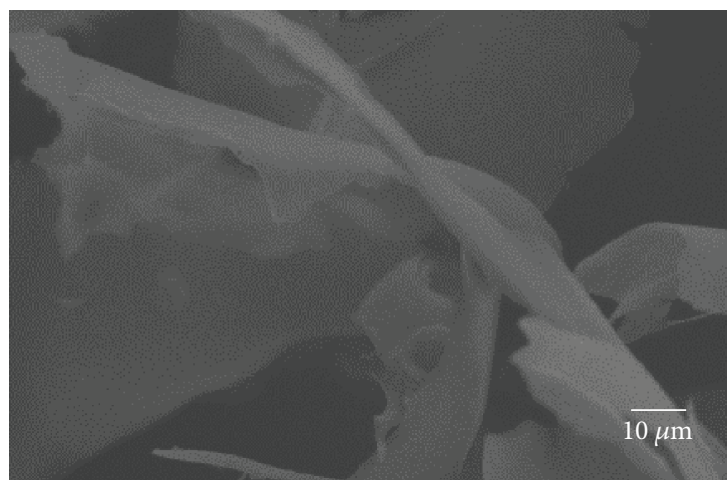

(g)

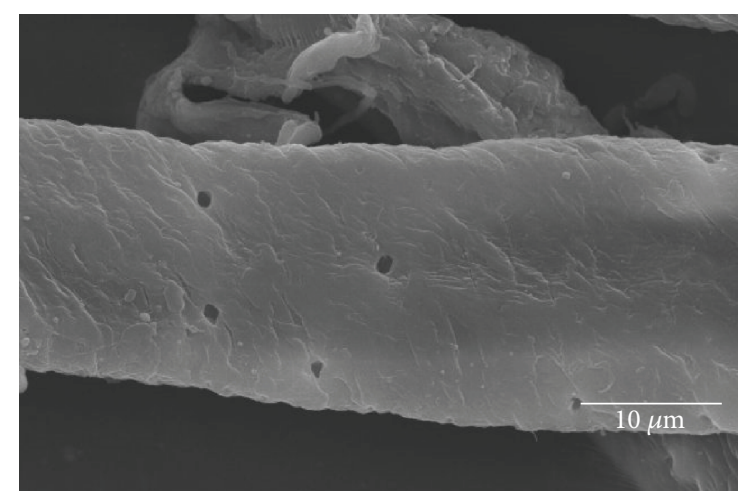

(b)

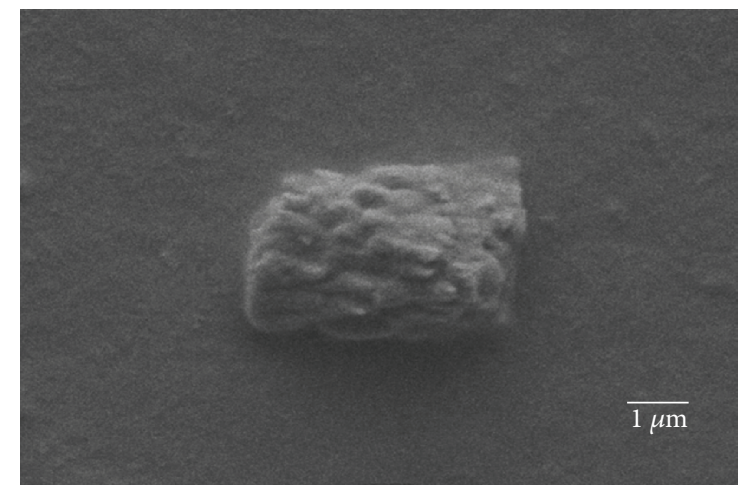

(d)

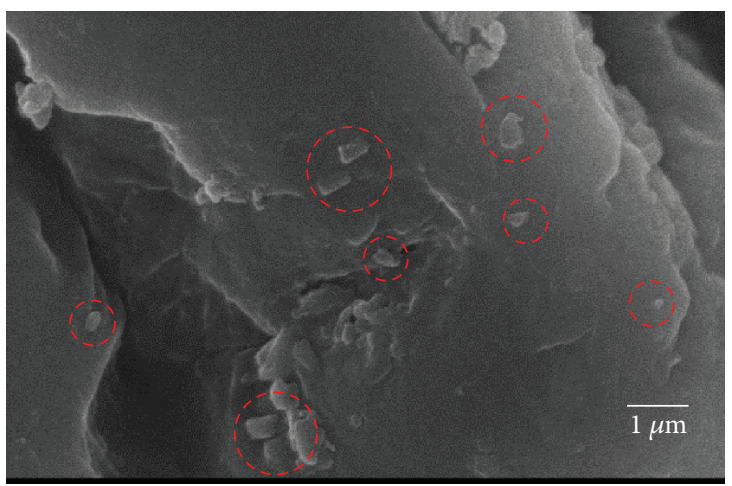

(f)

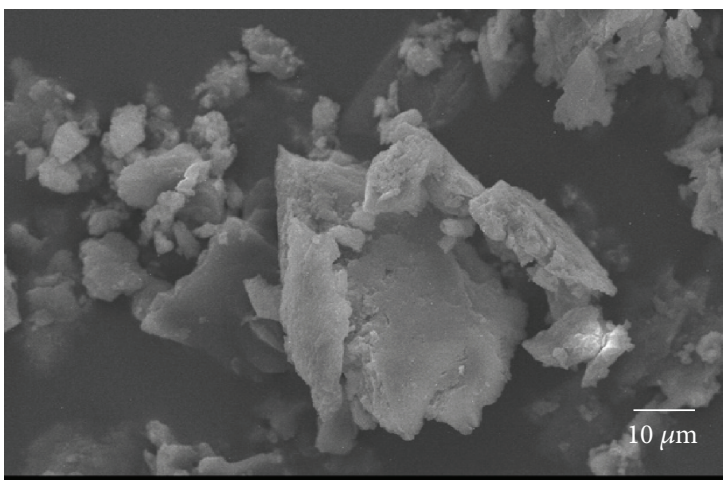

(h)

FIgUre 1: SEM micrographs of (a) raw ATW fiber, (b) extracted cellulose fiber, (c, d) CNC, (e, f) CNC/2-EHA, (g) lyophilized CNC, and (h) lyophilized CNC/2-EHA. 


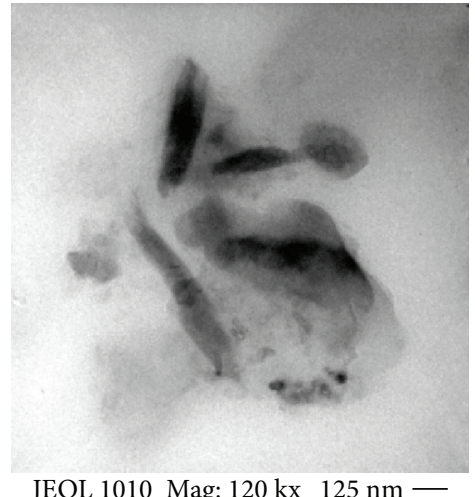

(a)

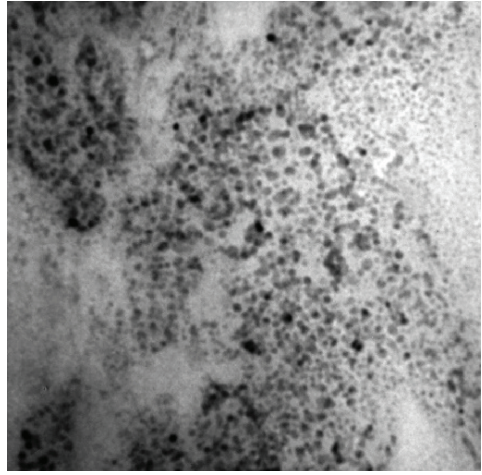

JEOL 1010 Mag: 300 kx 50 nm _

(b)

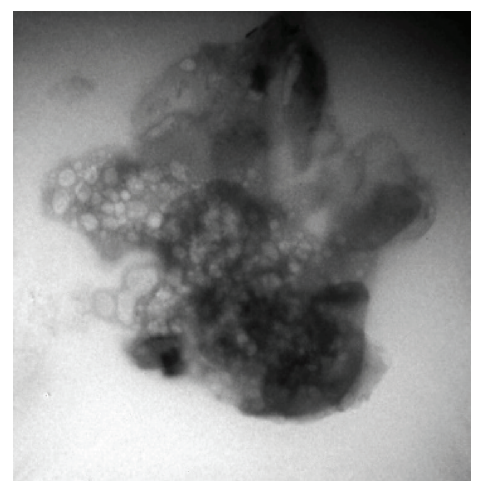

JEOL 1010 Mag: 100 kx 200 nm -

(c)

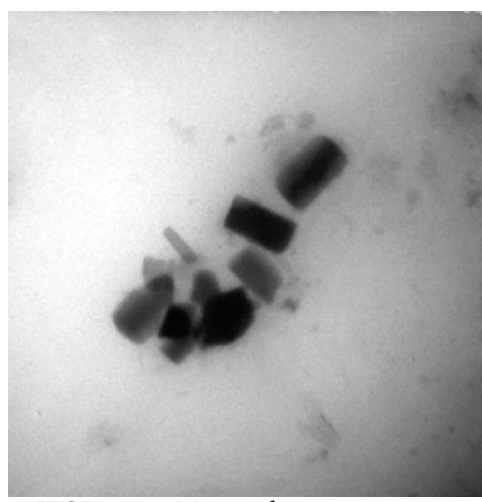

JEOL 1010 Mag: $80 \mathrm{kx} 250 \mathrm{~nm}-$

(d)

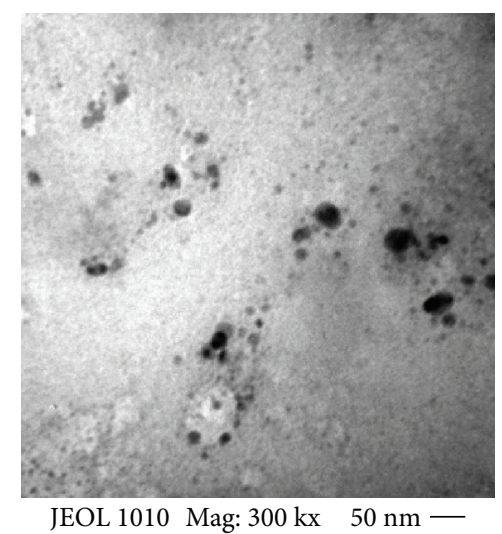

(e)

Figure 2: TEM micrographs of CNC (a-c), and CNC/2-EHA (d, e) exhibiting different morphologies.

the production of lamellar structure are the aspect ratio, concentration, hydrogen bonds, crystallinity, and surface charge of CNC [34].

A completely different morphology is observed for the CNC/2-EHA (Figure 1(h)) upon lyophilization, which is presented as aggregates of nanoparticles; no self-assembly was observed as pristine $\mathrm{CNC}$ due to the reduction of hydrogen bonds as a result of the polymer grafting.

Morphological details were obtained by TEM; Figure 2 shows TEM images of the pristine CNC and CNC/2-EHA. The results indicate that pristine $\mathrm{CNC}$ exhibited three different morphologies: rods (Figure 2(a)) with length ranging $590 \mathrm{~nm}$ and diameter ranging $100 \mathrm{~nm}$, spheres (Figure 2(b)) with apparent diameters in the order of $20 \mathrm{~nm}$, and the so-called porous network (Figure 2(c)) with apparent diameter ranging $80 \mathrm{~nm}$. The former morphologies has been related to the self-assembly process of short cellulose rods through interfacial hydrogen bonds and depends on the preparation method of cellulose fiber [35], source of cellulose, and production process of $\mathrm{CNC}[4,36]$. On the other hand, the formation of the porous network morphology is the result of the combination of several factors such as the lyophilization process, degree of dispersion of the $\mathrm{CNC}$ in water, and drying in the preparation of TEM sample $[36,37]$. A more detailed study is required to determine the proportion of each kind of morphology in the obtained $\mathrm{CNC}$; it is worthy to mention that the isolation of $\mathrm{CNC}$ fractions exhibiting different morphology is not possible by traditional methods of separation such as filtration or centrifugation so far $[36,37]$.

Our results are quite different from the those reported by Espino et al. who produced CNC from ATW bagasse fiber in the form of rods with lengths of $335 \pm 165 \mathrm{~nm}$ and diameters of $12 \pm 4$ and by means of acid hydrolysis [10], it is possible that the high shearing during preparation reduced the CNC size. On the other hand, two morphologies were found for CNC/2-EHA: rods (Figure 2(d)) with lengths and apparent diameters in the order of $500 \mathrm{~nm}$ and $\sim 140 \mathrm{~nm}$, respectively and spheres (Figure 2(e)) with apparent diameters of $\sim 20 \mathrm{~nm}$. Rods and spheres of CNC/2-EHA were observed like separated units; surface modification prevented agglomeration as reported by others [38].

Surface grafting was assessed by FTIR and XPS. Figure 3 shows the FTIR spectra of $\mathrm{CNC}$ and $\mathrm{CNC} / 2-\mathrm{EHA}$ which present a band in the region of 3500 to $3400 \mathrm{~cm}^{-1}$ corresponding to the $-\mathrm{OH}$ groups of the cellulose; the intensity of this band decreased upon 2-EHA grafting. An intense band is observed in $\sim 2897 \mathrm{~cm}^{-1}$ attributable to stretching vibrations of the $\mathrm{C}-\mathrm{H}$ bonds for both $\mathrm{CNC}$ and $\mathrm{CNC} / 2$ EHA. In addition, CNC/2-EHA presented a band at $\sim 2930 \mathrm{~cm}^{-1}$ corresponding to the characteristic stretching of the C-H bonds of the pendant groups [18].

The vibrations of deformation, wagging, and flexion of anhydroglucopyranose units are observed from 1800 to 


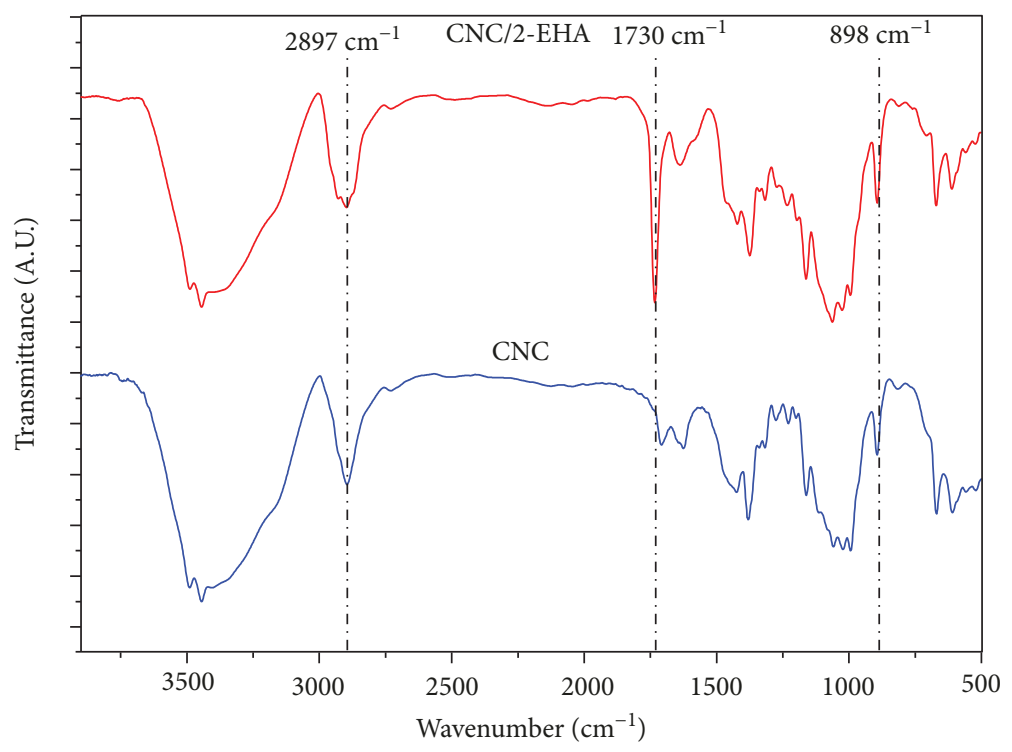

Figure 3: FTIR spectra of CNC and CNC/2-EHA.

$800 \mathrm{~cm}^{-1}$ and are consistent with other reports $[3,5,37,39$, 40]. The band at $\sim 892-898 \mathrm{~cm}^{-1}$ is associated to $\beta$-glycosidic linkages of cellulose [3] and to cellulose type II [39]. The CNC/2-EHA spectrum exhibited a strong band at $1730 \mathrm{~cm}^{-1}$, corresponding to the stretching of the carbonyl group of grafted 2-EHA [26, 41].

XPS was performed on the samples corroborate the 2EHA grafting. Figure 4 shows the survey spectra (a) and the deconvolution of the $\mathrm{C} 1 \mathrm{~s}$ peak for the CNC (b) and CNC/ 2-EHA (c). Survey spectra present the peaks for O1s, C1s, and $\mathrm{Sp} 2$. The $\mathrm{C} 1$ s peak deconvolution was carried out using the PeakFit v4.12 software and the Gaussian-Lorentzian method generating several groups: $\boldsymbol{C 1}$ corresponding to $\mathrm{C}-\mathrm{C}$ and $\mathrm{C}-\mathrm{H}$ bonds, $\mathrm{C} 2$ to $\mathrm{C}-\mathrm{O}$ bonds of alcohols and ethers, $\mathbf{C} \mathbf{3}$ to $\mathrm{O}-\mathrm{C}-\mathrm{O}$ and $\mathrm{C}=\mathrm{O}$ bonds, and $\mathbf{C} \boldsymbol{4}$ corresponding to $\mathrm{O}-\mathrm{C}=\mathrm{O}$ ester bond [15]. The $\mathrm{O} / \mathrm{C}$ ratio of $\mathrm{CNC}$ was 0.54 which is similar to that reported by other authors $[15,42]$; lower values of $\mathrm{O} / \mathrm{C}$ could be attributable to impurities [43]. The $\mathrm{O} / \mathrm{C}$ ratio for $\mathrm{CNC} / 2$-EHA was 0.45 , which is lower than that $\mathrm{CNC}$, due to the increase in the amount of carbon atoms from 2-EHA. On the other hand, the contribution of the $\mathbf{C 1}$ group of CNC/2-EHA decreased slightly in comparison with CNC upon grafting, from $49.4 \%$ to $47.8 \%$, possibly due to the impurities removing upon surface grafting [42].

The $\boldsymbol{C} 2$ group exhibited a slight decrease in the CNC/2EHA (30\%) sample compared with CNC (29.4\%) due to the loss of one glycol group of the anhydroglucopyranose at the position of carbons 2 or 3 as a consequence of grafting [44]. C3 was observed to slightly increase after grafting from $13.3 \%$ for $\mathrm{CNC}$ to $14.3 \%$ for $\mathrm{CNC} / 2-\mathrm{EHA}$, due to the formation of carbonyl groups in the cellulose unit and those from the grafted polymer chains [45]. The percentage of the bond type $\boldsymbol{C 4}$ increased from $7.3 \%$ to $8.5 \%$ for $\mathrm{CNC}$ and $\mathrm{CNC} / 2$ EHA, respectively, due to the contribution of the ester groups of the poly(2-EHA). Sulfur is present in both samples as result from sulfate groups during acid hydrolysis; sulfate groups remained after the grafting reaction since grafting position of on C2 or C3 of anhydroglucose [44], while sulfate groups are joined to C6 position [37].

On the other hand, TGA was used to estimate the grafting content and thermal stability of samples. Figure 5 shows the TGA thermograms (a) and DTGA (b) for CNC and CNC/2-EHA. Figure 5(a) shows three major mass loss events attributable to the elimination of adsorbed water $\left(\sim 50-120^{\circ} \mathrm{C}\right)$, cellulose degradation $\left(\sim 269-384^{\circ} \mathrm{C}\right)$, and the generation of carbonized residues $\left(\sim 450^{\circ} \mathrm{C}\right)$. The thermal degradation of the cellulose occurs in two stages: (a) the reduction of the chain size due to the rupture of bonds by the generation of free radicals, carboxyl groups, and carbonyls and (b) the depolymerization of the cellulose by the rupture of the glycosidic units and the formation of levoglucosan [40]. Figure 5(b) shows the derivative TGA traces for $\mathrm{CNC}$ exhibiting two decomposition events associated to the decomposition of sulfonated $\mathrm{CNC}$ and $\mathrm{CNC}\left(\sim 125-180^{\circ} \mathrm{C}\right.$ and $398-448^{\circ} \mathrm{C}$, resp.). CNC/2-EHA exhibited two decomposition events related to thermal decomposition of $\mathrm{CNC}$ and grafted polymer $\left(270-395^{\circ} \mathrm{C}\right.$ and $396-448^{\circ} \mathrm{C}$, resp.), as reported by others [38]. The grafting of poly(2-EHA) on the CNC surface improved the thermal stability of CNC because the poly(alkyl acrylates) exhibit higher degradation temperature $\left(405-415^{\circ} \mathrm{C}\right)$ [46]. The TGA results suggested that the 2-EHA grafted corresponded to $5 \mathrm{wt} . \%$.

The change in the surface energy of CNC due to poly(2EHA) grafting was evaluated through the Owens-Wendt approximation using the average of six measurements of the contact angles of sessile drops of various liquids on the surface of CNC samples at room temperature. The average values of the contact angles and the calculated surface energies are shown in Table 1 . It was observed that the contact angle of diiodomethane was lower in the CNC/2-EHA compared to the CNC; in the case of ethylene glycol and water, an opposite behavior was observed. The droplet of water exhibited a larger contact angle when deposited on $\mathrm{CNC} / 2-\mathrm{EHA}$ which is consistent with the literature related 


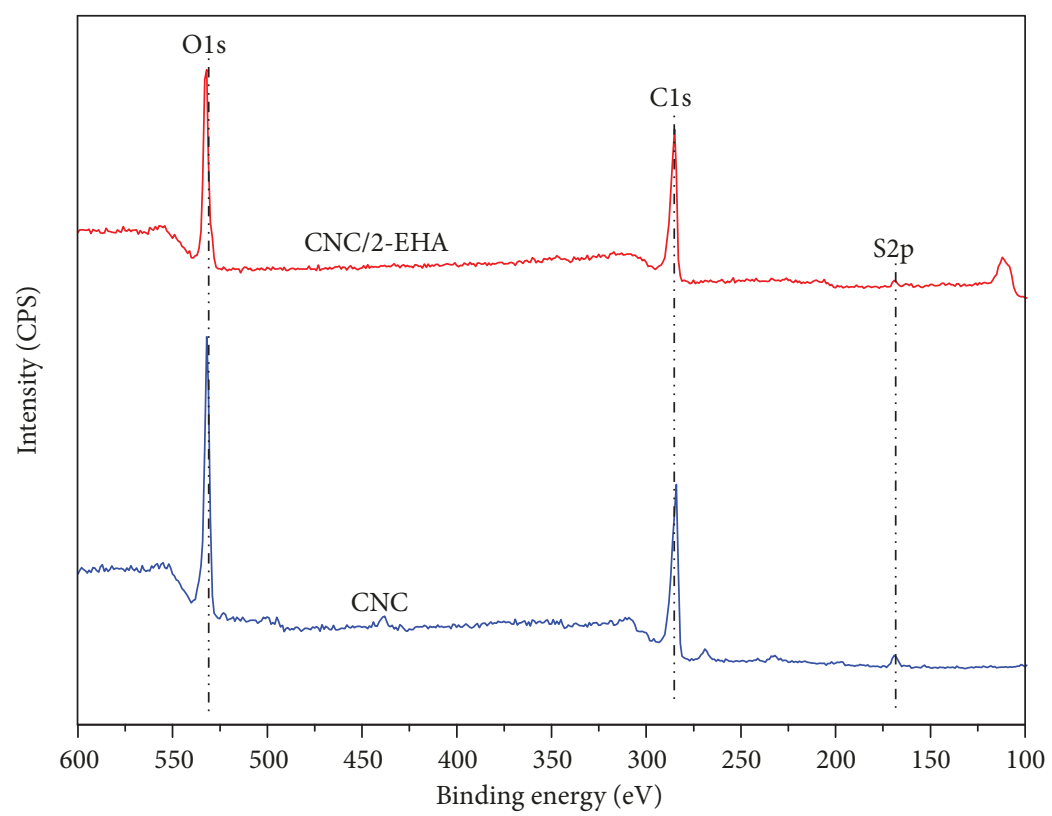

(a)

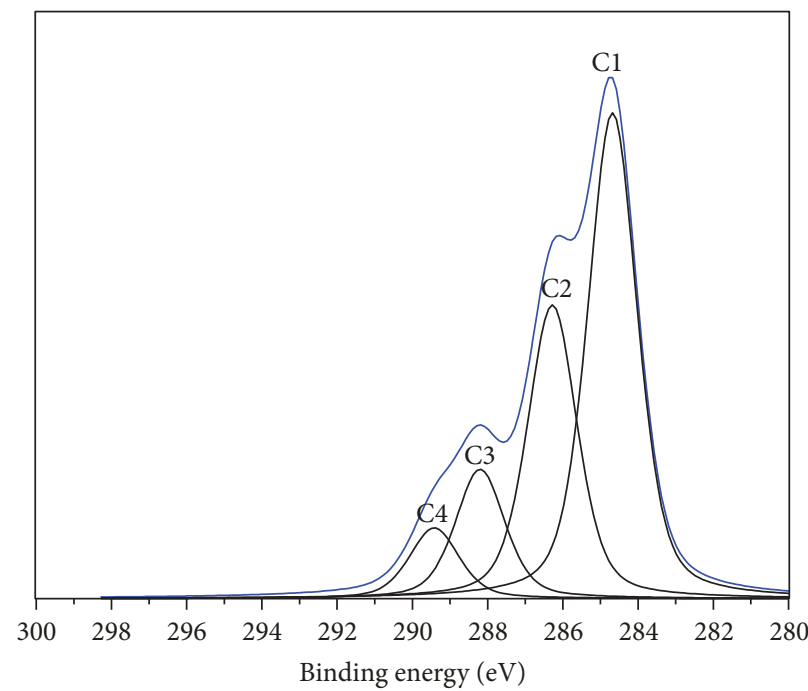

(b)

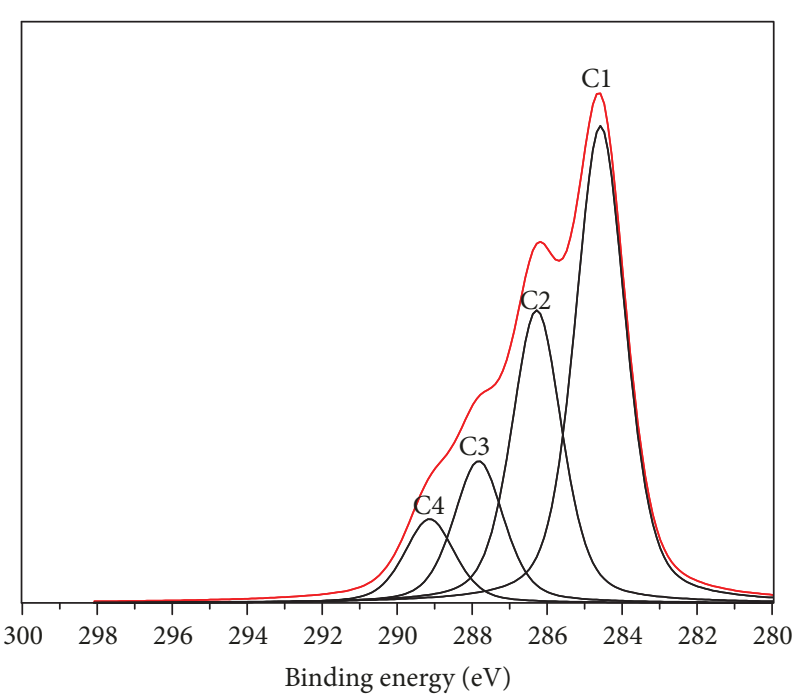

(c)

FIGURE 4: XPS survey spectra (a) and high resolution of C1s photoelectron spectra of CNC (b) and CNC/2-EHA (c).

to the surface-modified CNC $[14,15]$. The $R^{2}$ values for the linear regression for Owens-Wendt model were 0.94 and 0.84 for CNC and CNC/2-EHA, respectively; low $R^{2}$ value for CNC/2-EHA could be attributed to the roughness effect of sample surface [47]. The roughness of samples was determined through AFM analysis (AFM Bruker model Innova SPM in tapping mode) to be 23.8 and $31.8 \mathrm{~nm}$ for CNC and $\mathrm{CNC} / 2$-EHA, respectively.

The calculated dispersive component increased from 30.7 to $36.8 \mathrm{~mJ} / \mathrm{m}^{-2}$ upon grafting, whereas the polar component decreased from $22.9 \mathrm{~mJ} / \mathrm{m}^{-2}$ to $5.5 \mathrm{~mJ} / \mathrm{m}^{-2}$ as a result of the substitution of -OH by poly(2-EHA) and the formation of intramolecular hydrogen bonding of the carbonyl groups [14]. The decrease of the polar component and the increase of the dispersive component in the modified CNC suggest that $\mathrm{CNC} / 2 \mathrm{EHA}$ could be better dispersed in hydrophobic polymer matrices such as PLA.

The changes in the crystallinity degree of the cellulose upon extraction and grafting processes were evaluated by XRD. Figure 6 shows XRD diffractograms for bagasse fiber Agave tequilana Weber (FATW), extracted cellulose, CNC, and CNC/2-EHA. FATW exhibited the characteristic peaks for cellulose type I $\left(2 \theta=15.2^{\circ}, 22.6^{\circ}\right)$, and the peak at $2 \theta=24.7^{\circ}$ corresponds to silica [48] from the rich silica soils required for this type of crop [49]. The extracted cellulose shows 3 peaks at $2 \theta \sim 12.4^{\circ}, 20.2^{\circ}$, and $22.2^{\circ}$ corresponding to the structure of cellulose type II $[28,50,51]$; however, it is possible to observe some overlapped peaks corresponding 


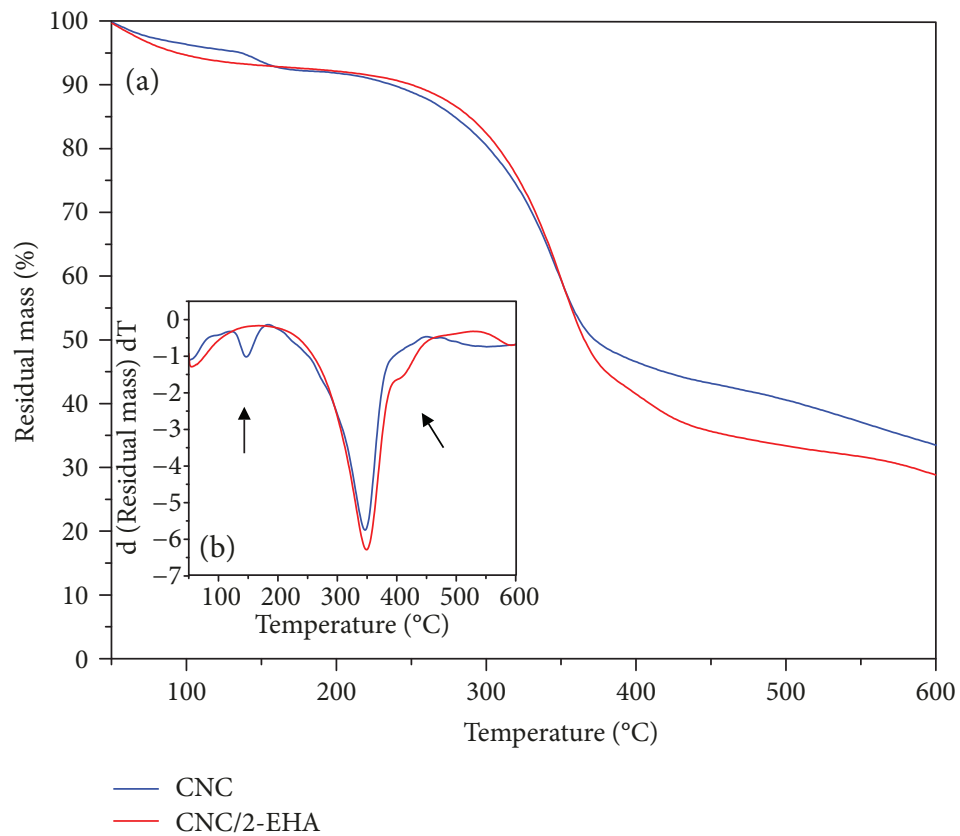

Figure 5: (a) TGA and (b) DTGA traces of CNC and CNC/2-EHA (nitrogen atmosphere, heating rate $10^{\circ} \mathrm{C} / \mathrm{min}$ ); arrows indicate the mass loss of water and grafted poly(2-EHA).

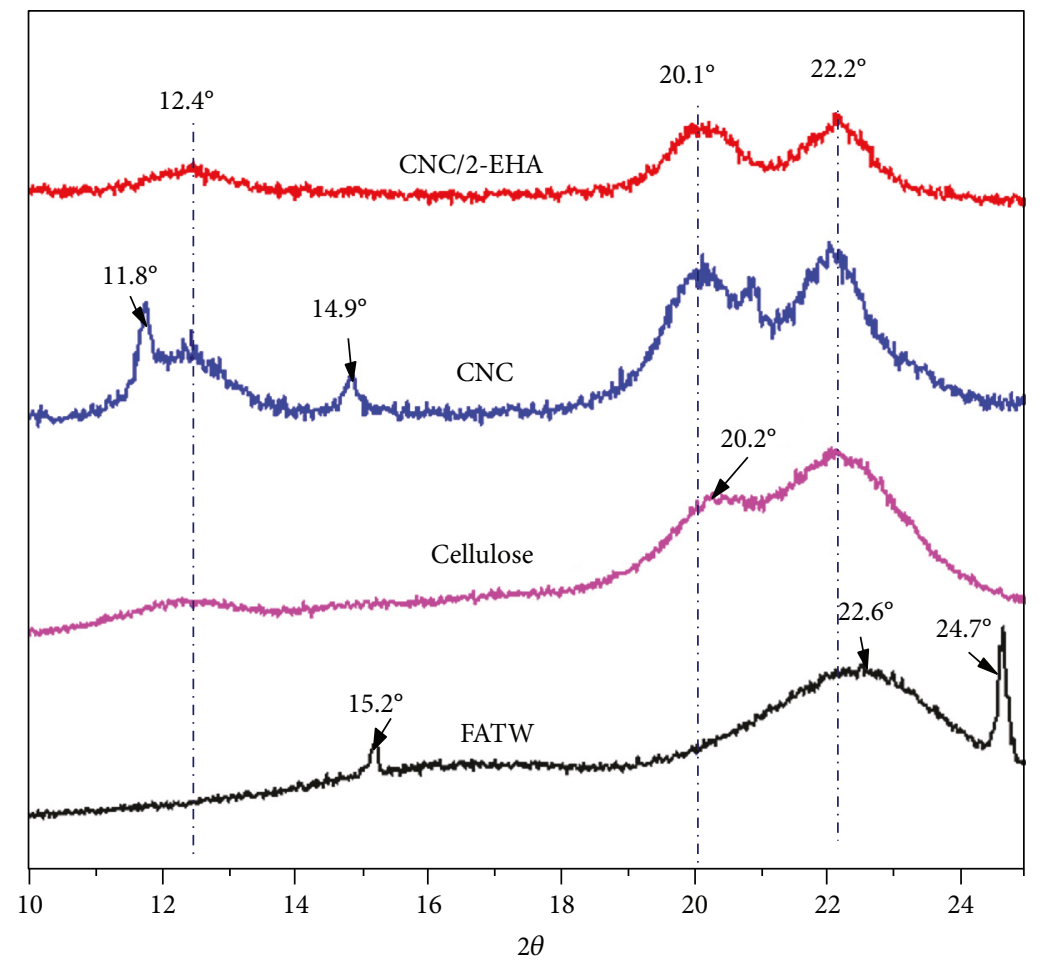

Figure 6: X-ray diffractograms of FATW, cellulose, CNC, and CNC/2-EHA.

to cellulose type I $\left(2 \theta=15.2^{\circ}, 22.6^{\circ}\right)$. The partial conversion from polymorphism I to II is due to alkali conditions (sodium hydroxide) and subsequent washing and drying processes employed to obtain cellulose [51]. CNC show both polymorphisms with defined peaks $\left(2 \theta=11.8^{\circ}, 12.4^{\circ}, 14.9^{\circ}\right.$, $20.1^{\circ}, 20.9^{\circ}$, and $22.2^{\circ}$ ); cellulose type I was preserved in part after the acid hydrolysis (isolation of $\mathrm{CNC}$ ); other authors have obtained $\mathrm{CNC}$ exhibiting a mixture of cellulose type I and II by using different contents of $\mathrm{H}_{2} \mathrm{SO}_{4}$ during the isolation process [52]. CNC/2-EHA presents peaks at $2 \theta=12.2^{\circ}$, $20.1^{\circ}$, and $22.2^{\circ}$ corresponding mainly to cellulose type II; however, it is possible that some peaks corresponding for cellulose I are overlapped within the amorphous zone. The intensity of the diffraction peaks for CNC/2-EHA is lower 
TABLE 2: Crystallinity index for cellulose I and II and estimated percentage of the polymorphisms in the samples.

\begin{tabular}{lcccc}
\hline \multirow{2}{*}{ Sample } & \multicolumn{2}{c}{$\begin{array}{c}\text { Crystallinity index (\%) } \\
\text { Cellulose I }\end{array}$} & $\begin{array}{c}\text { Cellulose II } \\
\text { polymorphe of the } \\
\text { Cellulose I }\end{array}$ & Cellulose II \\
\hline FATW & 64 & - & 100 & - \\
Cellulose & 74 & 73 & 57 & 43 \\
CNC & 89 & 94 & 48 & 52 \\
CNC/2-EHA & 69 & 69 & 49 & 51 \\
\hline
\end{tabular}

due to the amorphous characteristic of poly(2-ethyl hexyl acrylate). Cellulose II is the most important crystalline form from a technical and commercial point of view, because it is thermodynamically more stable [51], and suspensions of cellulose type II CNC have been found to have better rheological properties than their type I counterparts [53].

Crystallinity index (Table 2) was calculated using corresponding peaks for cellulose I $\left(I_{\mathrm{am}}=18^{\circ}, I_{200} \sim 22^{\circ}\right)$ and II $\left(I_{\mathrm{am}}=16^{\circ}, I_{1 \overline{1} 0} \sim 20^{\circ}\right)$. FATW presents low values of crystallinity corresponding to cellulose type I due to the presence of lignin and other organic materials; extracted cellulose presents an increase in the crystallinity index in the cellulose type I and type II. It is worthy to notice that the crystallinity index of both polymorphism increased being the type II with higher values upon the isolation of CNC, and after polymer grafting, both decreased at the same value due the presence of the amorphous polymer [54].

An estimation of the percentage of the concentration of the polymorphism type I and II in the samples was carried using the area of the diffraction peaks of the corresponding cellulose type. The deconvolution of the diffraction peaks was performed using the PeakFit v4.12 software and the Gaussian-Lorentzian method; in consequence, FATW exhibited 100\% cellulose I, extracted cellulose presented $57 \%$ type I and $43 \%$ type II, and after acid hydrolysis, the percentage of cellulose I diminished and that for cellulose II slightly increased (CNC) and remained at the same level after polymer grafting (CNC/2-EHA).

CNC was dispersed within PLA resin by melt blending in order to prepare PLA/CNC nanocomposites at different contents of CNC. Figure 7 presents SEM images of the fracture surface of PLA/CNC and PLA/(CNC/2-EHA) nanocomposites. Figures $7(\mathrm{a})-7(\mathrm{c})$ correspond to the surface of PLA/CNC at different loads of pristine $\mathrm{CNC}$ which was distributed as agglomerates indicating that the shear during processing was insufficient to disperse the $\mathrm{CNC}$ individually. On the other hand, Figures 7(d)-7(f) show the distribution of agglomerates $\mathrm{CNC} / 2$-EHA at different loadings. Figure 7(f) (at different magnifications) shows a CNC/2-EHA agglomerate at the highest concentration of modified CNC suggesting that the surface modification of $\mathrm{CNC}$ allowed its mixing until certain nanoparticle content.

Figures $8(\mathrm{a})-8(\mathrm{c})$ present TEM images of PLA/CNC nanocomposites at different lyophilized CNC contents, where the different morphologies of CNC discussed above coexisting in the nanocomposites. Indeed, Figures 8(c) and $8(\mathrm{e})$ show the coexistence of rods (red dotted circles) and spheres. TEM images showed CNC poorly dispersed in the PLA matrix consisted with the SEM observations.

Figures $8(\mathrm{~d})-8(\mathrm{f})$ show the distribution of $\mathrm{CNC} / 2-\mathrm{EHA}$ within PLA exhibiting the three morphologies; in Figure 8(e), the porous network (red arrows) coexisting with the other morphologies can be observed. Figure 8(f) presents a better dispersion of $(\mathrm{CNC} / 2-\mathrm{EHA})$, but it seems to be poorly distributed. PLA/(CNC/2-EHA) nanocomposites exhibited a better dispersion of modified CNC suggesting that the polymer grafted not only hindered the CNC aggregation but also allowed the dispersion of modified CNC during processing.

The effect of the degree of CNC dispersion on the rheological properties of PLA was evaluated [19]; it was reported that the rheological behavior of polymer nanocomposite is influenced by the type, concentration, surface area, aspect ratio, and chemical surface of nanoparticles [55]. In this sense, the surface modification of CNC is expected to produce an important impact on the rheological properties of polymer nanocomposites since the interactions among polymer-nanofiller are promoted favoring the formation of a nanofiller network within polymer matrix [55]. Thus, the potential use of CNC form ATW as nanorereinforcer for PLA was evaluated incorporating $\mathrm{CNC}$ (pristine and modified) at different proportions and determining its effect on the rheological properties of PLA/CNC nanocomposites. It is expected that grafted polymer promotes the polymer chain entanglement increasing the rheological properties.

Figure 9(a) presents the data for PLA and PLA/CNC nanocomposites showing that complex viscosity of PLA decreased continuously accounting for the $\sim 65 \%$ of initial value at the end of the experiment. The complex viscosity dropped rapidly during the first $15 \mathrm{~min}$; the molecular weight of PLA resin usually decreases during processing due to thermal degradation as reported by others [23, 56-59]. On the other hand, the complex viscosity of PLA/CNC nanocomposites showed lower values than PLA sample suggesting that $\mathrm{CNC}$ promoted polymer degradation during the processing due to the lower thermal stability of CNC; in fact, sulfate groups on the CNC promote the degradation of the PLA as reported by others $[60,61]$. It was noticed that the CNC concentration has a slight effect on the viscosity decrement. The presence of CNC stabilized PLA/CNC nanocomposites since viscosity remained unchanged at early stages of experiment over $12 \mathrm{~min}$.

Figure 9(b) shows the complex viscosity behavior of $\mathrm{PLA} /(\mathrm{CNC} / 2-\mathrm{EHA})$ nanocomposites with time at different $\mathrm{CNC} / 2$-EHA contents. The values of the complex viscosity of PLA decreased with CNC/2-EHA being slightly higher than those corresponding to PLA/CNC nanocomposites; it is possible that modified $\mathrm{CNC}$ promoted polymer degradation but in different manner than pristine $\mathrm{CNC}$ due to the ability of grafted poly(2-ethyl hexyl acrylate) to be hydrolyzed during processing [23]. It is interesting to notice that complex viscosity of PLA/(CNC-2EHA) nanocomposites increased with modified CNC content; this fact 


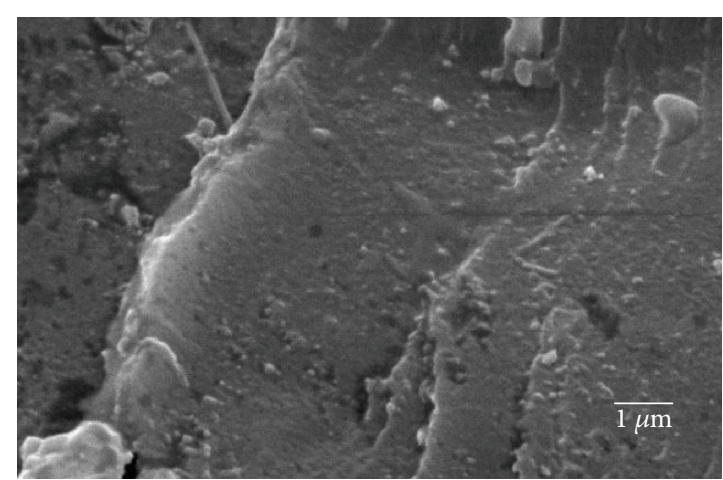

(a)

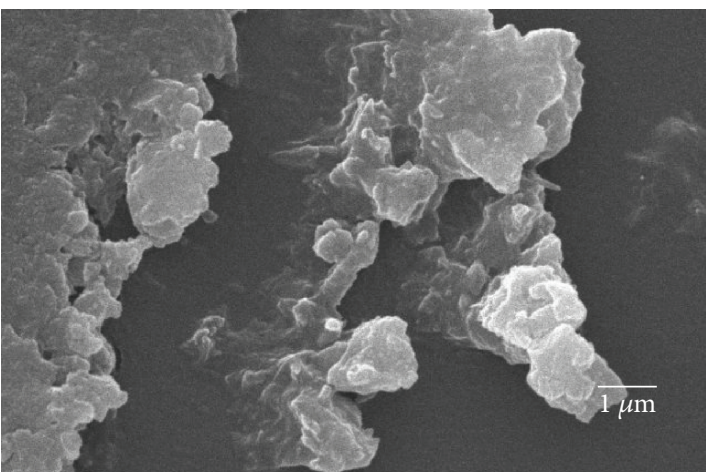

(c)

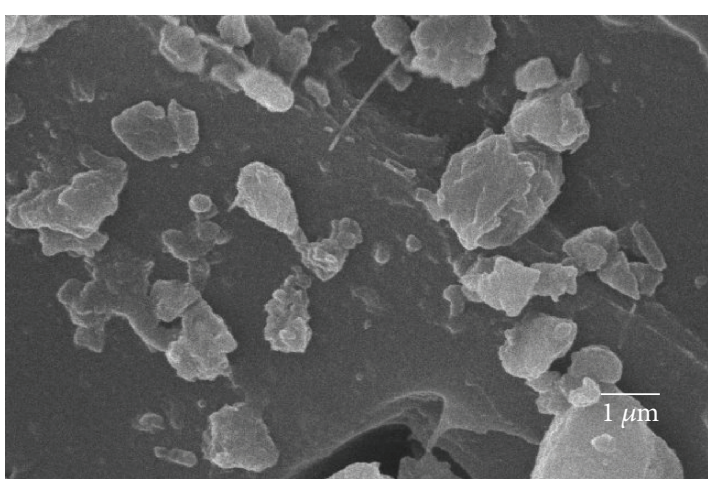

(e)

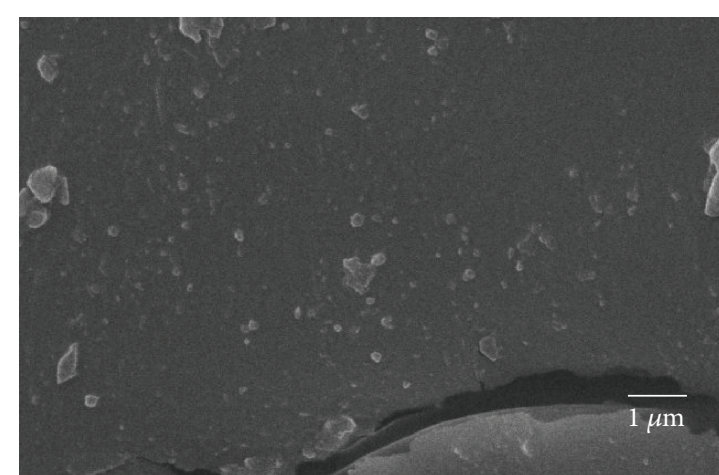

(b)

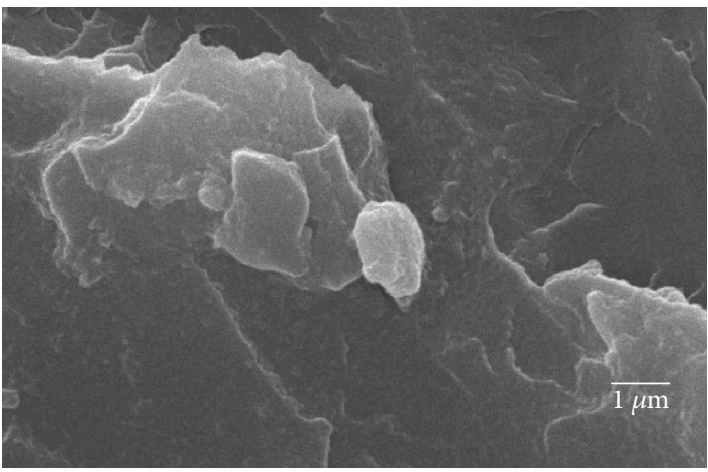

(d)

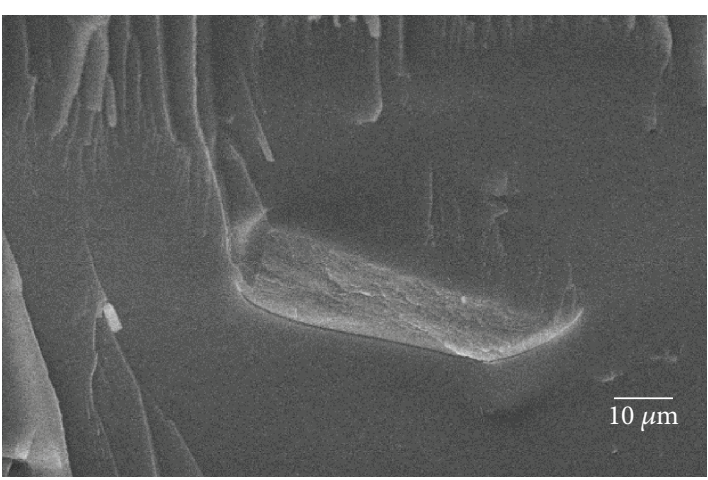

(f)

Figure 7: SEM micrographs of PLA/CNC nanocomposites (a) $0.5 \%$, (b) $1 \%$, and (c) $2 \%$ and PLA/(CNC/2-EHA) nanocomposites (d) $0.5 \%$, (e) $1 \%$, and (f) $2 \%$.

suggests that polymer grafting promoted not only better CNC dispersion but also matrix-nanoparticle interactions [56]. Probably, higher aspect ratio of CNC could produce better rheological properties.

\section{Conclusions}

CNC were obtained from ATW bagasse presenting three morphologies: rods, spheres, and porous networks with a wide range in nanometric dimensions. 2-EHA was successfully grafted $(\sim 5 \mathrm{wt} . \%)$ on the surface of $\mathrm{CNC}$ as a result the surface energy and the crystallinity index decreased, whereas the thermal stability was improved. The cellulose type I from the ATW bagasse yielded to a mixture of cellulose I and II after acid hydrolysis and alkali extraction process; the resulting CNC are composed by a mixture of both polymorphism which remained after surface grafting. The decrease of the polar component of the modified $\mathrm{CNC}$ suggests that CNC/2-EHA could be dispersed and promotes adhesion in hydrophobic polymer matrices, such as PLA.

The addition of CNC or CNC/2-EHA to PLA caused a decrease in the complex viscosity of the nanocomposites depending on the concentration of the nanofiller. Complex viscosity reduction was attributed to PLA degradation during processing promoted by thermal degradation of pristine and modified CNC. CNC concentration had a slight effect on the viscosity decrement for the PLA/CNC nanocomposites; 


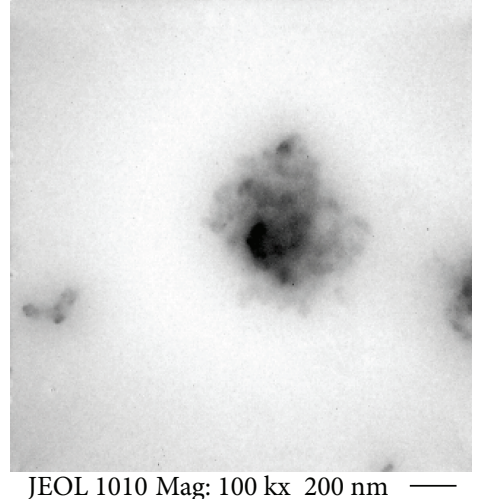

(a)

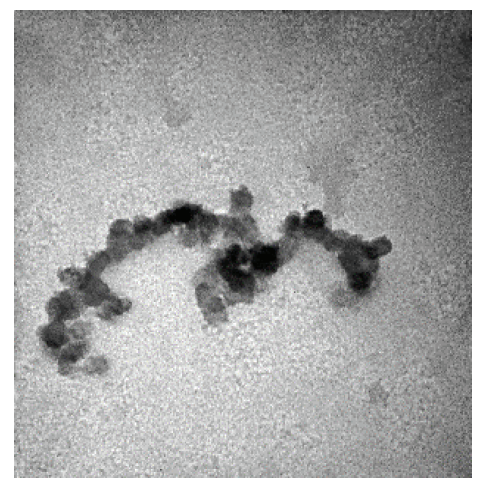

JEOL 1010 Mag: $100 \mathrm{kx} 200 \mathrm{~nm}$

(d)

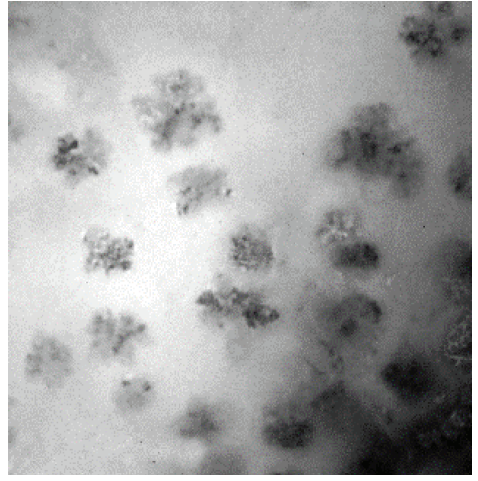

JEOL 1010 Mag: 100 kx 200 nm

(b)

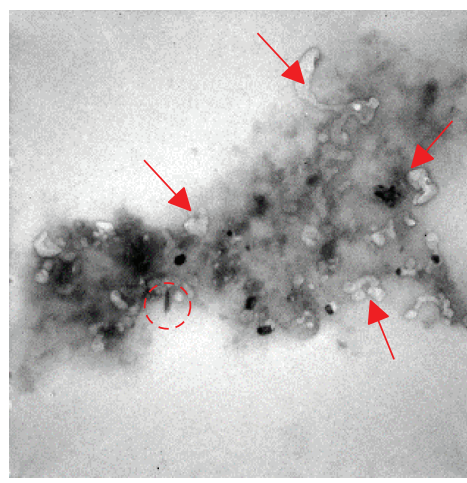

JEOL 1010 Mag: $100 \mathrm{kx} 200 \mathrm{~nm}$

(e)

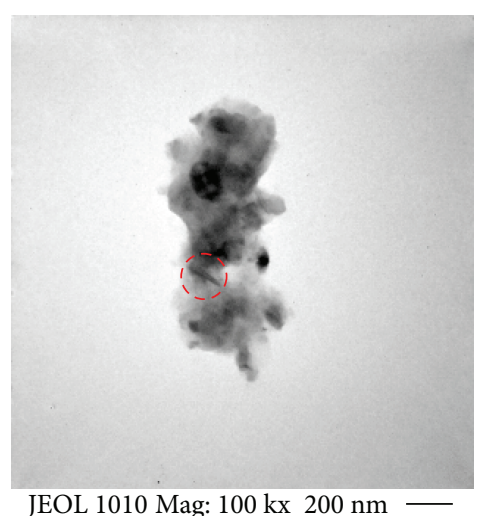

(c)

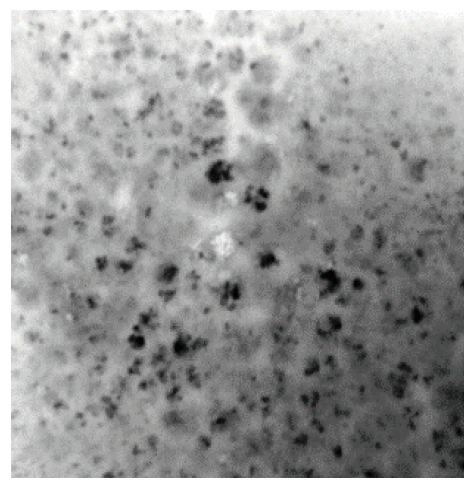

JEOL 1010 Mag: 100 kx $200 \mathrm{~nm}$

(f)

Figure 8: TEM micrographs of PLA/CNC nanocomposites (a) $0.5 \%$, (b) $1 \%$, and (c) $2 \%$ and PLA/(CNC/2-EHA) nanocomposites (d) $0.5 \%$, (e) $1 \%$, and (f) $2 \%$.

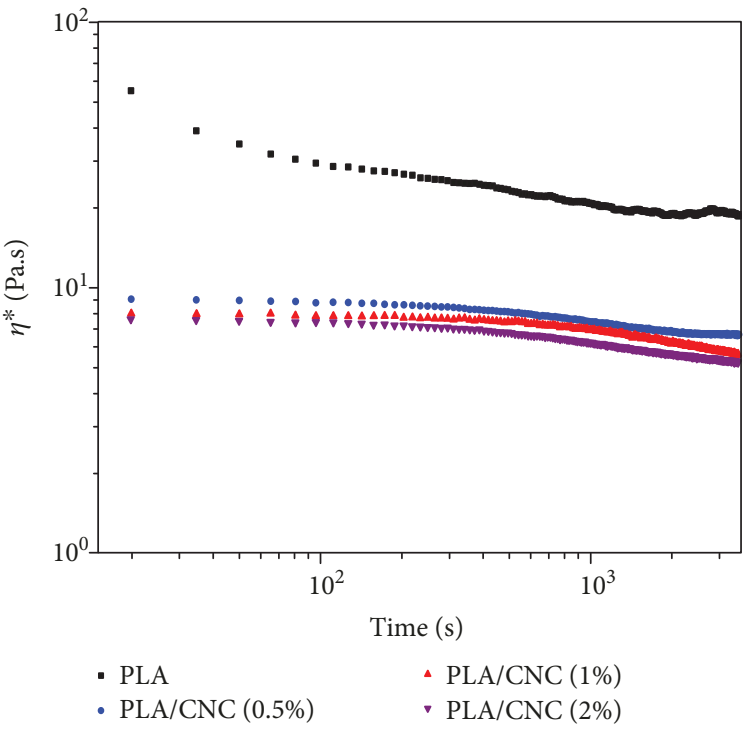

(a)

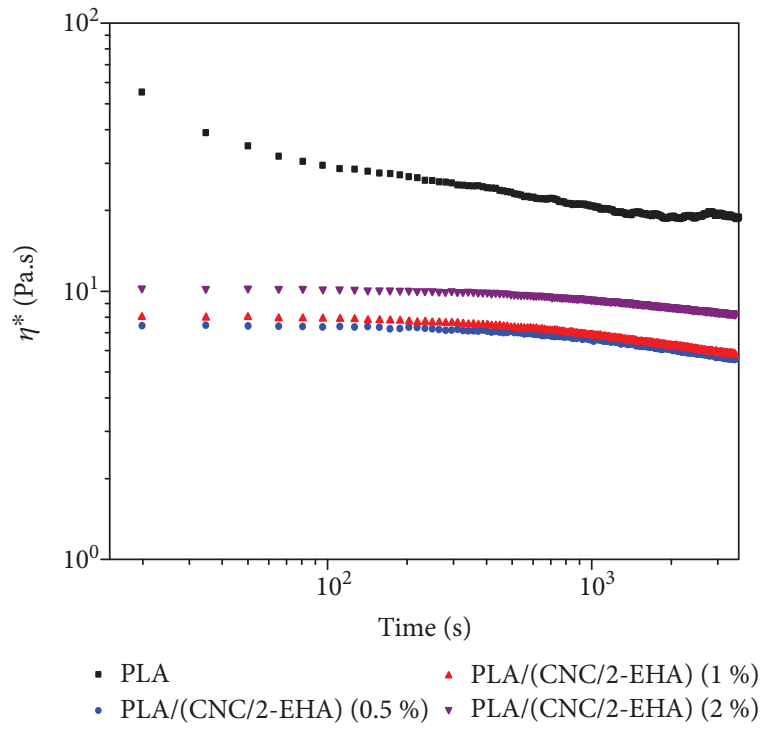

(b)

FIgure 9: Complex viscosity as a function of time for PLA nanocomposites containing (a) CNC and (b) CNC/2-EHA at different contents.

however, the complex viscosity of PLA/(CNC-2EHA) nanocomposites seems to increase with modified $\mathrm{CNC}$ content which suggests that the polymer grafting improves the interactions of PLA-CNC. Finally, the results suggest that $\mathrm{CNC} / 2$-EHA could be used as an alternative nanomaterial to modify melt viscosity of polymers. 


\section{Data Availability}

The data used to support the findings of this study are available from the corresponding author upon request.

\section{Conflicts of Interest}

The authors declare that they have no conflicts of interest.

\section{Acknowledgments}

The technical support from Santiago Duarte-Aranda (SEM), Wilberth Herrera Kao (TGA), Alejandro May-Pat (AFM), Daniel Aguilar (XRD), and William Cauich (XPS) is highly appreciated. The XRD and XPS analysis was performed at the National Laboratory of Nano and Biomaterials (financed by Fomix-Yucatan and Conacyt-Mexico), CINVESTAV-IPN Merida Unit. The authors thank Dr. Patricia Quintana for the access to LANNBIO. This study was partially financed by the project FOMIX Yucatan CICY YUC-2014-C17-247046.

\section{References}

[1] D. Bondeson, A. Mathew, and K. Oksman, "Optimization of the isolation of nanocrystals from microcrystalline cellulose by acid hydrolysis," Cellulose, vol. 13, no. 2, pp. 171-180, 2006.

[2] G. Bolio-López, A. Valadez-González, L. Veleva, and A. Andreeva, "Whiskers de celulosa a partir de residuos agroindustriales de banano: Obtención y caracterización," Revista mexicana de ingeniería química, vol. 10, no. 2, pp. 291-299, 2011.

[3] A. Kumar, Y. S. Negi, V. Choudhary, and N. K. Bhardwaj, "Characterization of cellulose nanocrystals produced by acidhydrolysis from sugarcane bagasse as agro-waste," Journal of Materials Physics and Chemistry, vol. 2, no. 1, pp. 1-8, 2014.

[4] H. Lu, Y. Gui, L. Zheng, and X. Liu, "Morphological, crystalline, thermal and physicochemical properties of cellulose nanocrystals obtained from sweet potato residue," Food Research International, vol. 50, no. 1, pp. 121-128, 2013.

[5] M. F. Rosa, E. S. Medeiros, J. A. Malmonge et al., "Cellulose nanowhiskers from coconut husk fibers: effect of preparation conditions on their thermal and morphological behavior," Carbohydrate Polymers, vol. 81, no. 1, pp. 83-92, 2010.

[6] P. Lu and Y.-L. Hsieh, "Preparation and characterization of cellulose nanocrystals from rice straw," Carbohydrate Polymers, vol. 87, no. 1, pp. 564-573, 2012.

[7] G. Iñiguez, N. Acosta, L. Martinez, J. Parra, and O. González, "Utilización de Subproductos de la Industria Tequilera. Parte 7. Compostaje de Bagazo de Agave y Vinazas Tequileras," Revista Internacional de Contaminación Ambiental, vol. 21, no. 1, pp. 37-50, 2010.

[8] P. Mignani, "Aprovechar los Desechos del Tequila," La Gaceta de la Universidad de Guadalajara, vol. 11, no. 713, p. 14, 2012.

[9] G. Iñiguez-Covarrubias, S. E. Lange, and R. M. Rowell, "Utilization of byproducts from the tequila industry: part 1: agave bagasse as a raw material for animal feeding and fiberboard production," Bioresource Technology, vol. 77, no. 1, pp. 2532, 2001.

[10] E. Espino, M. Cakir, S. Domenek, A. D. Román-Gutiérrez, N. Belgacem, and J. Bras, "Isolation and characterization of cellulose nanocrystals from industrial by-products of Agave tequilana and barley," Industrial Crops and Products, vol. 62, pp. 552-559, 2014.

[11] Y. Habibi, L. A. Lucia, and O. J. Rojas, "Cellulose nanocrystals: chemistry, self-assembly, and applications," Chemical Reviews, vol. 110, no. 6, pp. 3479-3500, 2010.

[12] J.-M. Raquez, Y. Habibi, M. Murariu, and P. Dubois, "Polylactide (PLA)-based nanocomposites," Progress in Polymer Science, vol. 38, no. 10-11, pp. 1504-1542, 2013.

[13] D. Bondeson and K. Oksman, "Polylactic acid/cellulose whisker nanocomposites modified by polyvinyl alcohol," Composites Part A: Applied Science and Manufacturing, vol. 38, no. 12, pp. 2486-2492, 2007.

[14] N. Lin, J. Huang, P. R. Chang, J. Feng, and J. Yu, "Surface acetylation of cellulose nanocrystal and its reinforcing function in poly(lactic acid)," Carbohydrate Polymers, vol. 83, no. 4, pp. 1834-1842, 2011.

[15] A. Junior de Menezes, G. Siqueira, A. A. S. Curvelo, and A. Dufresne, "Extrusion and characterization of functionalized cellulose whiskers reinforced polyethylene nanocomposites," Polymer, vol. 50, no. 19, pp. 4552-4563, 2009.

[16] K.-Y. Lee, J. J. Blaker, and A. Bismarck, "Surface functionalisation of bacterial cellulose as the route to produce green polylactide nanocomposites with improved properties," Composites Science and Technology, vol. 69, no. 15-16, pp. 2724-2733, 2009.

[17] M. Martínez-Sanz, M. A. Abdelwahab, A. Lopez-Rubio et al., "Incorporation of poly(glycidylmethacrylate) grafted bacterial cellulose nanowhiskers in poly(lactic acid) nanocomposites: improved barrier and mechanical properties," European Polymer Journal, vol. 49, no. 8, pp. 2062-2072, 2013.

[18] K. Littunen, U. Hippi, L.-S. Johansson et al., "Free radical graft copolymerization of nanofibrillated cellulose with acrylic monomers," Carbohydrate Polymers, vol. 84, no. 3, pp. 10391047, 2011.

[19] P. Cassagnau, "Melt rheology of organoclay and fumed silica nanocomposites," Polymer, vol. 49, no. 9, pp. 2183-2196, 2008.

[20] M. R. Kamal and V. Khoshkava, "Effect of cellulose nanocrystals (CNC) on rheological and mechanical properties and crystallization behavior of PLA/CNC nanocomposites," Carbohydrate Polymers, vol. 123, pp. 105-114, 2015.

[21] D. Bagheriasl, P. J. Carreau, B. Riedl, C. Dubois, and W. Y. Hamad, "Shear rheology of polylactide (PLA)-cellulose nanocrystal (CNC) nanocomposites," Cellulose, vol. 23, no. 3, pp. 1885-1897, 2016.

[22] N. Bitinis, R. Verdejo, J. Bras et al., "Poly(lactic acid)/natural rubber/cellulose nanocrystal bionanocomposites Part I. Processing and morphology," Carbohydrate Polymers, vol. 96, no. 2, pp. 611-620, 2013.

[23] Y. Lumelsky and M. S. Silverstein, "Biodegradable porous polymers through emulsion templating," Macromolecules, vol. 42, no. 5, pp. 1627-1633, 2009.

[24] M. N. Cazaurang-Martinez, S. R. Peraza-Sánchez, and C. A. Cruz-Ramos, "Dissolving-grade pulps from henequen fiber," Cellulose Chemistry and Technology, vol. 24, pp. 629-638, 1990.

[25] W. Y. Hamad and T. Q. Hu, "Structure-process-yield interrelations in nanocrystalline cellulose extraction," The Canadian Journal of Chemical Engineering, vol. 88, no. 3, pp. 392-402, 2010. 
[26] G. Canché-Escamilla, G. Rodríguez-Trujillo, P. J. HerreraFranco, E. Mendizábal, and J. E. Puig, "Preparation and characterization of henequen cellulose grafted with methyl methacrylate and its application in composites," Journal of Applied Polymer Science, vol. 66, no. 2, pp. 339-346, 1997.

[27] A. D. French and M. Santiago Cintrón, "Cellulose polymorphy, crystallite size, and the Segal crystallinity index," Cellulose, vol. 20, no. 1, pp. 583-588, 2013.

[28] A. Kljun, T. A. S. Benians, F. Goubet, F. Meulewaeter, J. P. Knox, and R. S. Blackburn, "Comparative analysis of crystallinity changes in cellulose I polymers using ATR-FTIR, X-ray diffraction, and carbohydrate-binding module probes," Biomacromolecules, vol. 12, no. 11, pp. 4121-4126, 2011.

[29] L. Segal, J. J. Creely, A. E. Martin Jr., and C. M. Conrad, “An empirical method for estimating the degree of crystallinity of native cellulose using the X-ray diffractometer," Textile Research Journal, vol. 29, no. 10, pp. 786-794, 1959.

[30] A. Agirre, J. Nase, E. Degrandi, C. Creton, and J. M. Asua, "Miniemulsion polymerization of 2-ethylhexyl acrylate. Polymer architecture control and adhesion properties," Macromolecules, vol. 43, no. 21, pp. 8924-8932, 2010.

[31] A. Hebeish and J. T. Guthrie, "The chemistry and technology of cellulose copolymers," Starch-Stärke, vol. 33, no. 12, p. 432,1981

[32] M. Shah, M. Majid, and M. Bari, Ceric-ion initiated graft copolymerization of methyl methacrylate on to cellulose [in Bangladesh], Chittagong University Studies, 1991.

[33] M.-C. Li, Q. Wu, K. Song, S. Lee, Y. Qing, and Y. Wu, "Cellulose nanoparticles: structure-morphology-rheology relationships," ACS Sustainable Chemistry \& Engineering, vol. 3, no. 5, pp. 821-832, 2015.

[34] J. Han, C. Zhou, Y. Wu, F. Liu, and Q. Wu, "Self-assembling behavior of cellulose nanoparticles during freeze-drying: effect of suspension concentration, particle size, crystal structure, and surface charge," Biomacromolecules, vol. 14, no. 5, pp. 1529-1540, 2013.

[35] J. Araki, M. Wada, S. Kuga, and T. Okano, "Flow properties of microcrystalline cellulose suspension prepared by acid treatment of native cellulose," Colloids and Surfaces A: Physicochemical and Engineering Aspects, vol. 142, no. 1, pp. 75-82, 1998.

[36] Y.-L. Hsieh, "Cellulose nanocrystals and self-assembled nanostructures from cotton, rice straw and grape skin: a source perspective," Journal of Materials Science, vol. 48, no. 22, pp. 7837-7846, 2013.

[37] P. Lu and Y.-L. Hsieh, "Preparation and properties of cellulose nanocrystals: rods, spheres, and network," Carbohydrate Polymers, vol. 82, no. 2, pp. 329-336, 2010.

[38] M. Haqani, H. Roghani-Mamaqani, and M. Salami-Kalajahi, "Synthesis of dual-sensitive nanocrystalline cellulose-grafted block copolymers of $\mathrm{N}$-isopropylacrylamide and acrylic acid by reversible addition-fragmentation chain transfer polymerization," Cellulose, vol. 24, no. 5, pp. 2241-2254, 2017.

[39] Q. Lu, W. Lin, L. Tang, S. Wang, X. Chen, and B. Huang, “A mechanochemical approach to manufacturing bamboo cellulose nanocrystals," Journal of Materials Science, vol. 50, no. 2, pp. 611-619, 2015.

[40] N. A. Rosli, I. Ahmad, and I. Abdullah, "Isolation and characterization of cellulose nanocrystals from Agave angustifolia fibre," BioResources, vol. 8, no. 2, 2013.
[41] L. Qin, J. Qiu, M. Liu et al., "Mechanical and thermal properties of poly (lactic acid) composites with rice straw fiber modified by poly (butyl acrylate)," Chemical Engineering Journal, vol. 166, no. 2, pp. 772-778, 2011.

[42] G. Siqueira, J. Bras, and A. Dufresne, "New process of chemical grafting of cellulose nanoparticles with a long chain isocyanate," Langmuir, vol. 26, no. 1, pp. 402-411, 2010.

[43] M. Jonoobi, J. Harun, M. Mishra, and K. Oksman, "Chemical composition, crystallinity and thermal degradation of bleached and unbleached kenaf bast (Hibiscus cannabinus) pulp and nanofiber," BioResources, vol. 4, no. 2, pp. 626-639, 2009.

[44] T. Doba, C. Rodehed, and B. Ranby, "Mechanism of graft co-polymerization onto polysaccharides initiated by metal ion oxidation reactions of model compounds for starch and cellulose," Macromolecules, vol. 17, no. 12, pp. 2512 2519, 1984.

[45] X. Shen, J. L. Shamshina, P. Berton, G. Gurau, and R. D. Rogers, "Hydrogels based on cellulose and chitin: fabrication, properties, and applications," Green Chemistry, vol. 18, no. 1, pp. 53-75, 2016.

[46] N. Grassie and J. G. Speakman, "Thermal degradation of poly(alkyl acrylates). I. Preliminary investigations," Journal of Polymer Science Part A-1: Polymer Chemistry, vol. 9, no. 4, pp. 919-929, 1971.

[47] K.-Y. Lee, F. Quero, J. J. Blaker, C. A. S. Hill, S. J. Eichhorn, and A. Bismarck, "Surface only modification of bacterial cellulose nanofibres with organic acids," Cellulose, vol. 18, no. 3, pp. 595-605, 2011.

[48] T. Zheng, X. Xu, J. Pan, S. Xiao, and J. Lv, "Studies of preparation and characteristics in borosilicate photosensitive glassceramics," Materials Sciences and Applications, vol. 3, no. 2, pp. 98-102, 2012.

[49] M. Bautista Justo, L. García Oropeza, J. Barboza-Corona, and L. Parra Negrete, "El Agave tequilana Weber y la producción de tequila," Acta Universitaria, vol. 11, no. 2, 2001.

[50] A. M. Hindeleh and D. J. Johnson, "Crystallinity and crystallite size measurement in cellulose fibres: 1. Ramie and Fortisan," Polymer, vol. 13, no. 9, pp. 423-430, 1972.

[51] F. Torres, O. Troncoso, C. Torres, and C. Grande, "Cellulose based blends, composites and nanocomposites," in Advances in Natural Polymers, S. Thomas, P. Visakh, and A. P. Mathew, Eds., pp. 21-54, Springer, 2013.

[52] G. Sèbe, F. Ham-Pichavant, E. Ibarboure, A. L. C. Koffi, and P. Tingaut, "Supramolecular structure characterization of cellulose II nanowhiskers produced by acid hydrolysis of cellulose I substrates," Biomacromolecules, vol. 13, no. 2, pp. 570-578, 2012.

[53] Y. Yue, C. Zhou, A. D. French et al., "Comparative properties of cellulose nano-crystals from native and mercerized cotton fibers," Cellulose, vol. 19, no. 4, pp. 1173-1187, 2012.

[54] M. Golshan, M. Salami-Kalajahi, H. Roghani-Mamaqani, and M. Mohammadi, "Poly (propylene imine) dendrimer-grafted nanocrystalline cellulose: doxorubicin loading and release behavior," Polymer, vol. 117, pp. 287-294, 2017.

[55] Y. C. Ching, M. Ershad Ali, L. C. Abdullah et al., "Rheological properties of cellulose nanocrystal-embedded polymer composites: a review," Cellulose, vol. 23, no. 2, pp. 1011-1030, 2016.

[56] Q. Meng, M.-C. Heuzey, and P. J. Carreau, "Control of thermal degradation of polylactide/clay nanocomposites during melt 
processing by chain extension reaction," Polymer Degradation and Stability, vol. 97, no. 10, pp. 2010-2020, 2012.

[57] L. D’Urso, M. Acocella, G. Guerra, V. Iozzino, F. de Santis, and R. Pantani, "PLA melt stabilization by high-surface-area graphite and carbon black," Polymer, vol. 10, no. 2, p. 139, 2018.

[58] K. S. Seo and J. D. Cloyd, "Kinetics of hydrolysis and thermal degradation of polyester melts," Journal of Applied Polymer Science, vol. 42, no. 3, pp. 845-850, 1991.

[59] V. Speranza, A. De Meo, and R. Pantani, "Thermal and hydrolytic degradation kinetics of PLA in the molten state," Polymer Degradation and Stability, vol. 100, pp. 37-41, 2014.

[60] E. Fortunati, F. Luzi, D. Puglia, R. Petrucci, J. M. Kenny, and L. Torre, "Processing of PLA nanocomposites with cellulose nanocrystals extracted from Posidonia oceanica waste: innovative reuse of coastal plant," Industrial Crops and Products, vol. 67, pp. 439-447, 2015.

[61] P. Dhar, S. M. Bhasney, A. Kumar, and V. Katiyar, "Acid functionalized cellulose nanocrystals and its effect on mechanical, thermal, crystallization and surfaces properties of poly (lactic acid) bionanocomposites films: a comprehensive study," Polymer, vol. 101, pp. 75-92, 2016. 


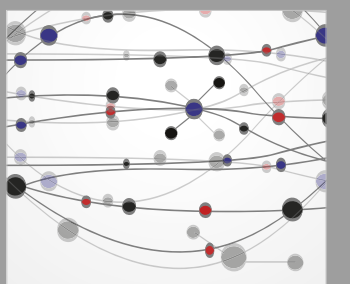

The Scientific World Journal
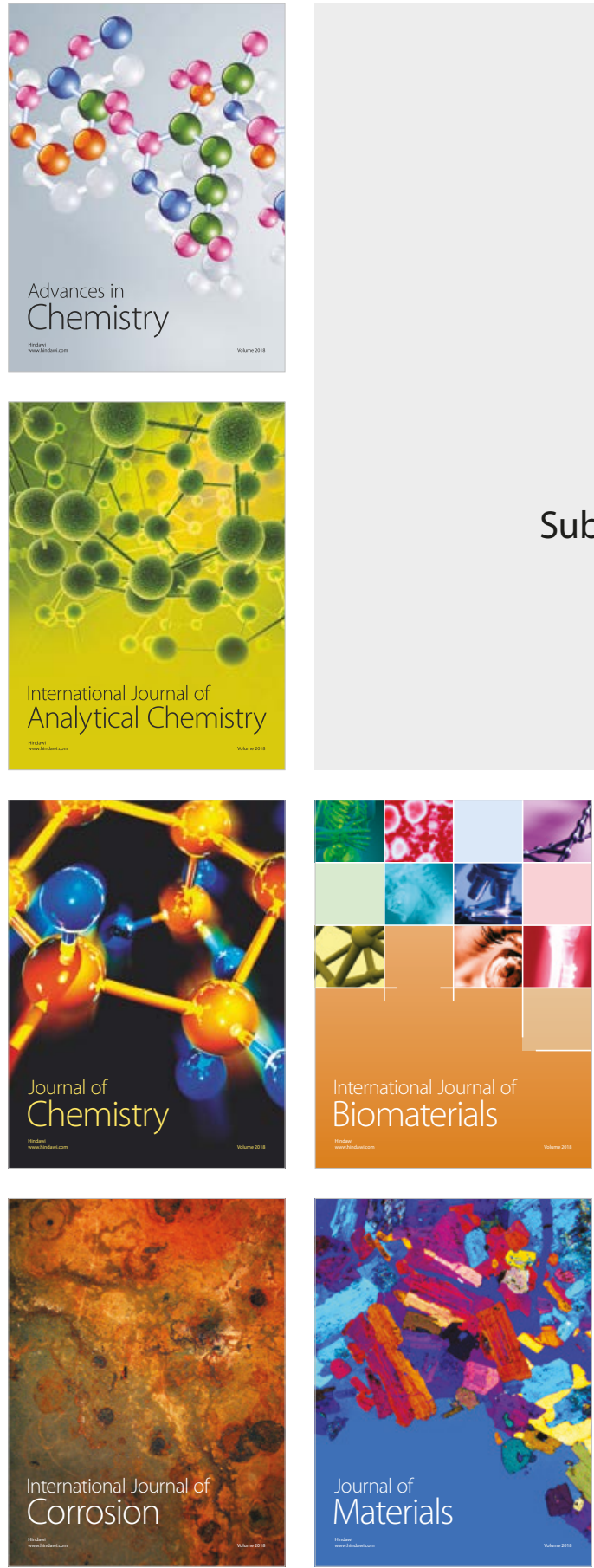

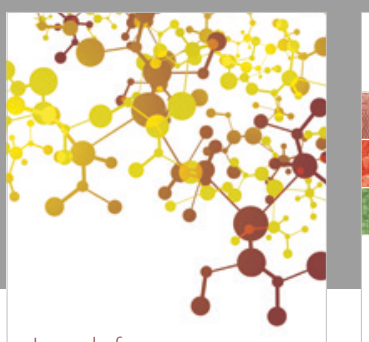

Journal of

Applied Chemistry
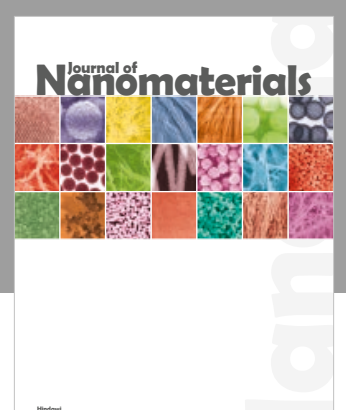

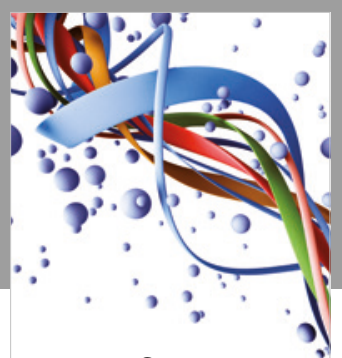

Scientifica

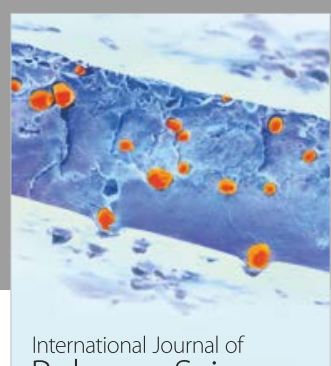

Polymer Science

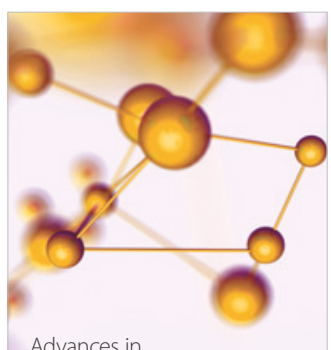

Physical Chemistry
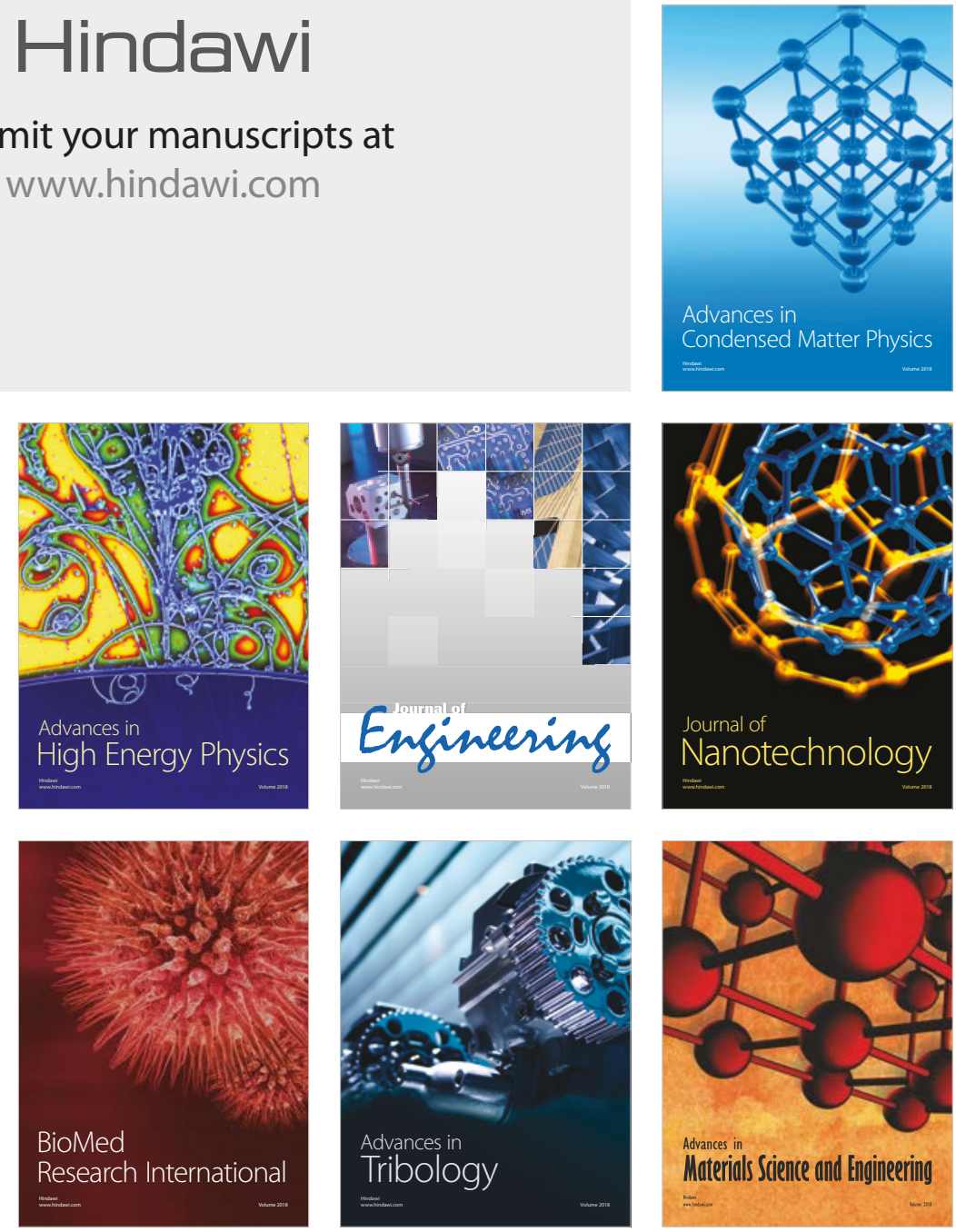